\title{
IDENTIFYING THE DETERMINANTS OF BEHAVIORAL INTENTION TO USE SMARTPHONE ALCOHOL USE DISORDER (AUD) RECOVERY APPS
}

\author{
by \\ Rijuta Menon \\ Hon. B.Sc., University of Toronto, 2017 \\ A thesis \\ presented to Ryerson University \\ in partial fulfillment of the \\ requirements for the degree of \\ Master of Science in Management \\ in the program of \\ Master of Science in Management \\ Toronto, Ontario, Canada, 2020 \\ (CRijuta Menon, 2020
}




\section{AUTHOR'S DECLARATION}

I hereby declare that I am the sole author of this thesis. This is a true copy of the thesis, including any required final revisions, as accepted by my examiners.

I authorize Ryerson University to lend this thesis to other institutions or individuals for the purpose of scholarly research.

I further authorize Ryerson University to reproduce this thesis by photocopying or by other means, in total or in part, at the request of other institutions or individuals for the purpose of scholarly research.

I understand that my thesis may be made electronically available to the public. 


\begin{abstract}
IDENTIFYING THE DETERMINANTS OF BEHAVIORAL INTENTION TO USE SMARTPHONE ALCOHOL USE DISORDER (AUD) RECOVERY APPS
\end{abstract}

\author{
Rijuta Menon, 2020 \\ Master of Science in Management \\ Ryerson University
}

Recently, non-traditional modes of treatment using mobile devices have been explored to supplement recovery from Alcohol Use Disorder (AUD). Although the literature has shown promising results of their efficacy, mobile interventions generally remain underused. The Unified Theory of Acceptance and Use of Technology (UTAUT), was applied to explain the findings on the acceptance and use of Smartphone AUD recovery apps. The researcher surveyed 160 participants from addiction treatment facilities across Ontario and from various AUD recovery support groups on social media. The results demonstrated social influence to be the key antecedent to behavioral intention to use these apps and suggested a potential positive relationship between behavioral intention and use behavior. This study also highlighted the app features considered to be the most important to participants. The findings contribute to the IT acceptance literature as it pertains to addiction apps and offers practical implications for health care providers and app developers. 


\section{ACKNOWLEDGEMENTS}

I extend my deepest gratitude to my thesis supervisor, Dr. Julien Meyer, for his guidance, patience, and direction, in helping me navigate the world of research and academia. I am also extremely grateful for the sound advice, support, and the encouragement, he provided throughout this process.

I am grateful to my committee members, Dr. Linying Dong and Dr. Pria Nippak, for their involvement in my thesis and for their assistance in its improvement.

I am extremely grateful to the kind folks at the addiction treatment centres from where I got the data for this paper. This research would not have been possible without the help, generosity, and the participation, of the directors, staff, and the clients at these centres. Thank you all very much!

It has been an amazing opportunity working with many of Ryerson's talented professors and my fellow classmates. I especially want to thank Saman Feroze and Guneet Kaur for making this master's program experience an enjoyable one.

Finally, I want to thank my family and loved ones. I am extremely grateful to my parents, Pranoti and Ravi, and my brother, Priyan, for supporting me in all my endeavors from the very beginning. I would not be here without your continuous love and encouragement! I am also extremely grateful to Nadia Singh who, with her endless positivity, humor, and support, has helped provide me with the balance I needed throughout the process. Last, but not least, I want to thank my better half, Valay Shah. You have been my rock through everything, and I am eternally grateful to you for your love, help, and selflessness, in getting me to the finish line! 


\section{TABLE OF CONTENTS}

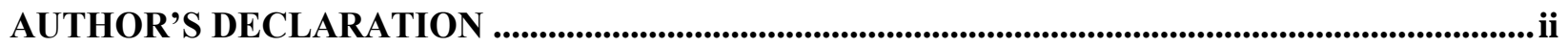

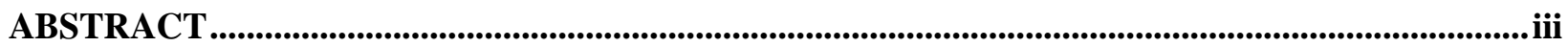

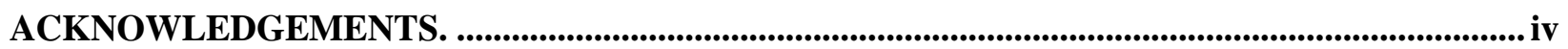

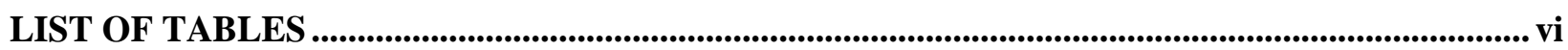

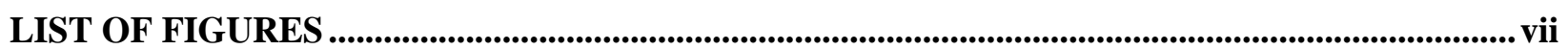

INTRODUCTION

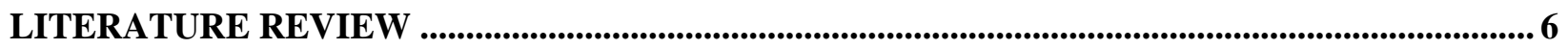

Efficacy of Smartphone AUD Recovery Apps ................................................................................... 6

Smartphone AUD Recovery Apps: Acceptance and Adoption .................................................................. 6

mHealth for Mental Health: Acceptance and Adoption ................................................................8

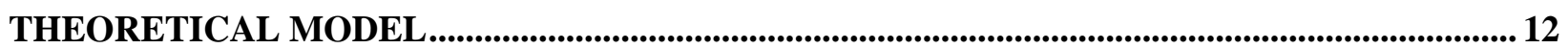

Unified Theory of Acceptance and Use of Technology (UTAUT) ................................................... 12

Unified Theory of Acceptance and Use of Technology (UTAUT2) ...................................................... 14

Applicability and Relevance of UTAUT2 Constructs ............................................................................ 16

HYPOTHESES AND RESEARCH MODEL............................................................................................ 17

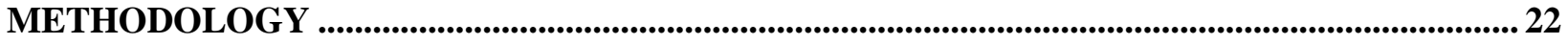

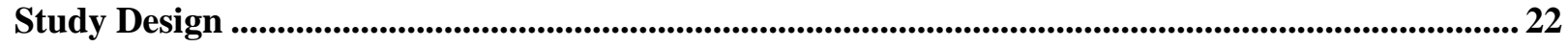

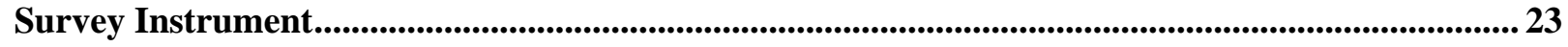

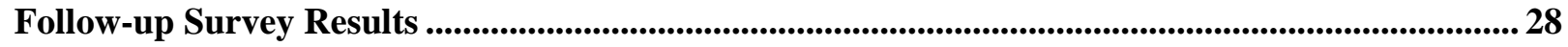

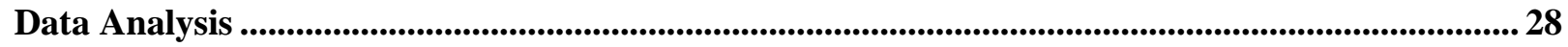

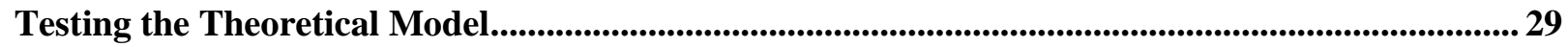

RESULTS ........................................................................................................................................................................ 30

Descriptive Statistics ..................................................................................................................................................... 31

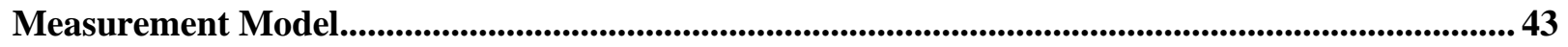

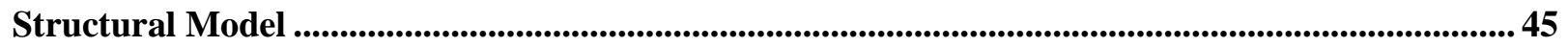

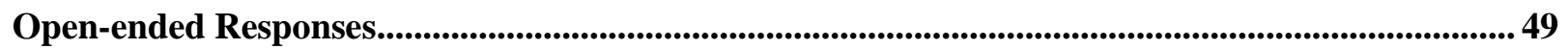

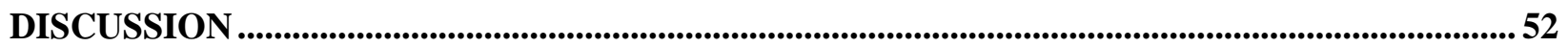

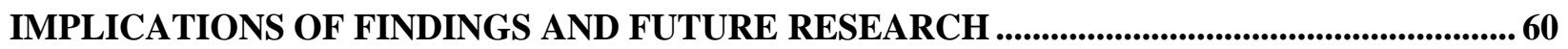

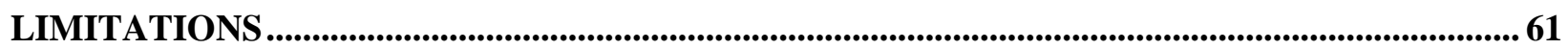

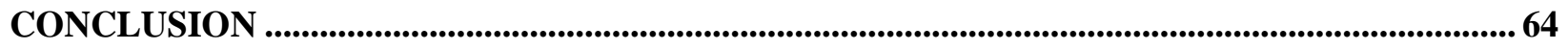

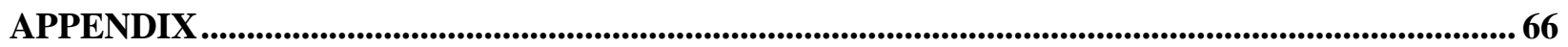

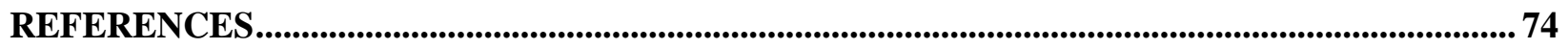




\section{LIST OF TABLES}

Table 1: Heavy Drinking: Sex and Age Group ..................................................................2

Table 2: A Comparison of Questionnaire Items Operationalizing UTAUT Constructs ...............24

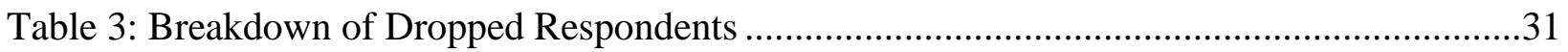

Table 4: Level of Identification with AUD and Participants' Mean Scores on UTAUT

Constructs.

Table 5: Group Statistics: Level of Identification with the Definition of AUD and Survey

Version .36

Table 6: Independent Samples t-test: Level of Identification with AUD by Survey Version .......36

Table 7: Questions to Investigate Participants' Knowledge of Smartphone AUD Recovery Apps and their Use History

Table 8: Prior Awareness of the Existence of Smartphone AUD Recovery Apps and Participants' Mean Scores on UTAUT Constructs..... .38

Table 9: Group Statistics: Prior Awareness of the Existence of Smartphone AUD Recovery Apps and Mean Scores on UTAUT Questionnaire Items.

Table 10: Independent Samples t-test: Prior Awareness of the Existence of Smartphone AUD Recovery Apps and Mean Scores on UTAUT Questionnaire Items.

Table 11: Construct Reliability and Validity.... .44

Table 12: Discriminant Validity (HTMT Ratios) .45

Table 13: Simple Model: Path Coefficients and Significance of Relationships .47

Table 14: Complete Model: Path Coefficients and Significance of Relationships .49

Table 15: List of Open-ended Questions on the First Survey .50 


\section{LIST OF FIGURES}

Figure 1: UTAUT Research Model ................................................................................. 14

Figure 2: Research Model: Determinants of Behavioral Intention and Usage of Smartphone AUD

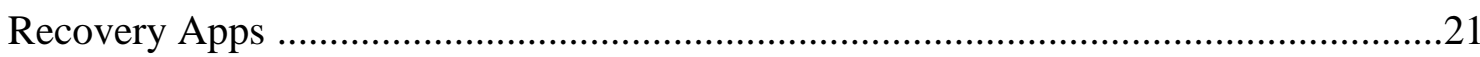

Figure 3: Comparison of the Age Groups of Respondents in the Statistics Canada Population and

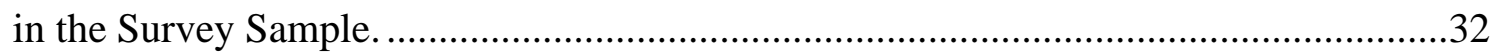

Figure 4: Survey Version and Self-identification with AUD ..............................................35

Figure 5: Usage Frequency of Smartphone AUD Recovery Apps by Survey Version ...............43

Figure 6: Simple Model: Path Coefficients and $\mathrm{R}^{2}$.................................................................46

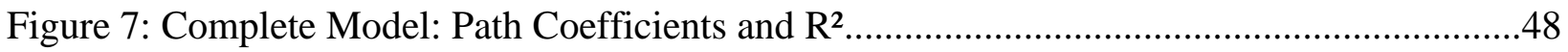




\section{INTRODUCTION}

In Canada, excessive substance use bears significant economic and healthcare costs. In 2014, the economic cost (a combination of healthcare, lost productivity, criminal justice, and other direct costs) of substance use in Canada was $\$ 38.4$ billion-the substance associated with the highest cost ( $\$ 14.6$ billion) being alcohol (Canadian Centre on Substance Use and Addiction, \& Canadian Institute for Substance Use Research, 2018). In the same year, the substances with the three highest fatalities amounted to 67,515 for tobacco, 47,562 for alcohol, and 2,396 for opioid-related deaths (Canadian Centre on Substance Use and Addiction, \& Canadian Institute for Substance Use Research, 2018).

In 2017, 78\% of Canadians, 15 years of age and older, reported past-year alcohol consumption of at least one time (Health Canada, 2018). The National Institute on Alcohol Abuse and Alcoholism (NIAAA, 2014) considers problem drinking that becomes severe as falling into a medical diagnosis known as "alcohol use disorder" (AUD). Used interchangeably with "alcohol addiction", an AUD is defined as a "chronic relapsing brain disease characterized by compulsive alcohol use, loss of control over alcohol intake, and a negative emotional state when not using" (NIAAA, 2014). While the percentage of Canadians who suffer from an AUD is currently unknown, data is available on the percentage of Canadians who engage in "heavy drinking”.

Statistics Canada defines "heavy drinking" as the consumption of "5 or more drinks on one occasion, 12 or more times over the past year" (Statistics Canada, 2018). One standard drink refers to any drink that contains 13.6 grams of "pure" alcohol (Middlesex-London Health Unit, 2017). Thus, one drink can mean 12 ounces of 5\% alcohol beer, cider or cooler, 5 ounces of $12 \%$ wine, or 1.5 ounces of $40 \%$ hard liquor (i.e. vodka, rum, whiskey, or gin) (Canadian Centre on 
Substance Use and Addiction, 2018). While "binge", or heavy drinking, is neither a necessary nor sufficient condition for an individual to receive the diagnosis of AUD, those who are heavy drinkers are at a significantly higher risk to develop an AUD than individuals who drink only occasionally (American Addiction Centers, 2019). Moreover, heavy drinkers are far more likely to have an AUD diagnosis than those who do not engage in heavy drinking (American Addiction Centers, 2019). Table 1 illustrates the latest available data on the percentage of Canadians who engaged in heavy drinking, filtered by sex and by age group.

Table 1.

Heavy Drinking: Sex and Age Group

\begin{tabular}{|c|c|c|c|c|c|c|}
\hline \multicolumn{7}{|c|}{ 2018: Heavy drinking in the Canadian population (excluding territories) } \\
\hline \multicolumn{7}{|c|}{ Sex } \\
\hline & Males & & Females & & Both & \\
\hline Age group (in years) & Number of persons & Percent & Number of persons & Percent & Number of persons & Percent \\
\hline $12-17$ & 33,300 & 2.9 & 43,800 & 4.0 & 77,100 & 6.9 \\
\hline 18-34 & $1,390,900$ & 33.5 & 970,900 & 23.8 & $2,361,800$ & 57.3 \\
\hline $35-49$ & $1,005,000$ & 28.4 & 628,100 & 17.5 & $1,633,100$ & 45.9 \\
\hline $50-64$ & 885,600 & 23.7 & 537,700 & 14.2 & $1,423,300$ & 37.9 \\
\hline 65 and over & 299,100 & 10.6 & 151,900 & 4.6 & 451,000 & 15.2 \\
\hline Total & $\mathbf{3 , 6 1 3 , 9 0 0}$ & & $\mathbf{2 , 3 3 2 , 4 0 0}$ & & $5,946,300$ & \\
\hline
\end{tabular}

Note. Data from Statistics Canada (2018)

From Table 1, there was a total of 5.95 million Canadians, 12 years of age or older, who engaged in heavy drinking (Statistics Canada, 2018). This was $19.1 \%$ of the entire Canadian population (Statistics Canada, 2018). Males were more likely to be heavy drinkers (60.8\%) compared to females (39.2\%). The age group with the highest percentage of heavy drinkers was 18-34 years (57.3\%), followed by 35-49 years (45.9\%), and 50-64 years (37.9\%).

Treatment and engagement with recovery activities are integral to avoiding disease progression which can result in disability and premature death (Miller, 2015). The conventional 
treatment strategies for addiction revolve around outpatient (community), inpatient (hospital), residential, withdrawal management centers, and continuing care settings (Canadian Centre on Substance Use and Addiction, \& Canadian Executive Council of Addictions, 2017). Treatment for addiction, like treatment for other mental illnesses, entails cognitive, behavioral, pharmacological, or a combination of these interventions (Winerman, 2013). How treatment for addiction differs from treatment for other mental illnesses, however, is that it may also explore abstinence alongside a wide range of therapies (Mental Health America, 2018).

A publication by the NIAAA (2014) found that most people with an alcohol use disorder (AUD) can benefit from some form of treatment. In fact, research shows that "about one-third of people who are treated for alcohol problems have no further symptoms a year later" and "many others substantially reduce their drinking and report fewer alcohol-related problems" (NIAAA, 2014). Given the promise of treatment in alleviating problematic alcohol use, it is important to determine whether those with such conditions indeed connect with treatment services or otherwise engage in treatment-seeking behaviors.

Although individuals with drinking problems accept traditional person-delivered treatment modalities (i.e. brief interventions, motivational enhancements, and cognitive behavior therapies) and find them to be effective, substantial treatment barriers exist in the implementation of and access to traditional interventions (Fowler, Holt, \& Joshi, 2016). Traditional in-person interventions usually require substantial time and money, they are resource intensive, depend predominantly on the skill of the clinician, and can be stigmatizing (Fowler et al, 2016). The authors posit these accessibility barriers and stigma as being potential reasons for explaining the low rates of treatment-seeking among problem drinkers-only 15-25\% of individuals with drinking problems seek treatment (Fowler et al, 2016). 
Given this low rate of treatment-seeking, Fowler et al (2016) put forward Mobile health (mHealth) interventions as the solution to addressing this problem as it offers a delivery of treatment that is widespread, cost-effective, dependable, individualized, and destigmatized (Fowler et al, 2016). mHealth interventions are an information and communication technologies (ICT) tool that deliver health services using mobile telephones and other related devices (Guo, Zhang, \& Sun, 2016). They can improve the delivery processes of healthcare services by providing support and services to healthcare providers (HCPs) through education, diagnosis support, patient management, and to facilitate communication between HCPs and consumers (Gagnon, Ngangue, Payne-Gagnon, \& Desmartis, 2016). The benefits of mHealth stem from its accessibility and portability due to its ability to provide remote medical monitoring and consultation (Guo et al, 2016). This is important because it allows users to access round-theclock support for their healthcare needs, in the convenience of their own home. It also streamlines healthcare and reduces healthcare costs (Guo et al, 2016). mHealth addiction recovery Smartphone applications (apps) bypass the treatment barriers of traditional treatment modalities by enabling anytime access, and contain minimal end-user costs (Hoeppner et al,2017). The most common functions of alcohol and substance use addiction recovery apps were found to include the provision of information, motivation enhancement, social support facilitation, and the provision of feedback (Savic, Best, Rodda, \& Lubman, 2013). They have also been shown to support abstinence and promote positive treatment outcomes for patients in a variety of studies (Chih et al, 2013; Liang, Han, Du, Zhao, \& Hser, 2018; Mares et al, 2016; and Zhu et al, 2018). From these studies, a couple (Chih et al, 2011; Muroff et al, 2017) have shown that most patients who used the apps during the experiment continued to be active users of the 
apps several months post-discharge. Despite this accessibility and these promising results, mHealth apps remain underused (Becker et al, 2014; Vo et al, 2019).

Since behavioral intention to use technology was found to lead to usage behavior (Venkatesh, Morris, Davis, \& Davis, 2003), identifying the determinants of behavioral intention to use technology is a helpful starting point, as this predicts later technology use. The purpose of this thesis, therefore, is to identify the determinants of behavioral intention to use Smartphone AUD recovery apps among those who self-identify as having an AUD. The research questions are as follows:

1) What are the determinants of behavioral intention to use Smartphone alcohol addiction recovery apps?

2) Does behavioral intention to use addiction recovery apps predict consequent usage of these apps?

To answer these questions, the Unified Theory of acceptance and use of technology (UTAUT) was applied and the following hypotheses were formulated: (1) performance expectancy, (2) effort expectancy, and (3) social influence, are all positively correlated with behavioral intention to use Smartphone AUD recovery apps. Furthermore, behavioral intention was hypothesized to positively correlate with use behavior of these apps, while the construct of facilitating conditions was hypothesized to positively correlate with use behavior. Since alcohol is the most widely used substance in Canada and its use also bears the greatest economic consequences compared to other substances, the focus was on mHealth alcohol addiction recovery apps. 
The remainder of this paper is organized by a review of the literature, followed by a subsequent section on the hypotheses and research model. Next, the methodology is described, and the results are discussed. The implications of this study are also explored along with the next steps for future research, and the study's limitations. Finally, the overall conclusions are drawn.

\section{LITERATURE REVIEW}

\section{Efficacy of Smartphone AUD Recovery Apps}

Alcohol addiction apps have been proven to be useful — or at the very least, shown promise in, aiding addiction recovery, in a variety of studies and systematic literature reviews (Chih et al, 2013; Fowler et al, 2016; Kazemi et al, 2017; Liang et al, 2018; Mares et al, 2016; Quanbeck, Chih, Isham, \& Gustafson, 2014; Sawares et al, 2017; and Zhu et al, 2018). Some studies have even shown that most patients who have used such apps during treatment have continued using them for several months post-discharge (Chih et al, 2011; Muroff et al, 2017). Given the promise and potential efficacy of alcohol addiction apps, the objective of this literature review will be to uncover existing knowledge on the antecedents of behavioral intention (used interchangeably with acceptance) of addiction recovery apps.

\section{Smartphone Addiction Recovery Apps: Acceptance and Adoption}

A thorough review of the literature yielded scarce results for studies investigating the antecedents of acceptance and use of alcohol addiction recovery apps in particular; however, a few studies were found that partially investigated this question. In a cross-sectional survey study of 259 participants in four outpatient substance use disorder programs, Ashford, Lynch, and Curtis (2018) found that the vast majority (94\%) of participants owned mobile phones with 64\% of them owning a mobile phone with app capabilities. Moreover, they found that most of the 
respondents (70\%) indicated their interest in using mobile apps to help them recover from alcohol or substance use (Ashford et al, 2018). This study shows that those who have addiction generally have the technical equipment to use addiction recovery apps, however, they do not use them. Ashford et al's (2018) study highlights a need to understand the cognitive factors that lead to the use of a technology.

A qualitative study by Crane, Garnett, Brown, West, and Michie (2017) investigated the factors influencing the usability of a Smartphone app to reduce excessive alcohol consumption among first-time and experienced users. Three main themes emerged in the study. Participants felt "lost and unsure of what to do next" while using the app. Correspondingly, participants indicated their desire for the developers to "make the app easy to use" and to also "make the app rewarding and beneficial to use" (Crane et al, 2017). The authors concluded that both new and existing users needed an alcohol reduction app to be easy to use, rewarding, aesthetically pleasing, offer ongoing help, and provide compelling reasons to sustain usage (Crane et al, 2017).

In another qualitative study that also evaluated a specific alcohol reduction app, the authors calculated participants' app usage data and explored users' feedback (Attwood, Parke, Larsen, \& Morton, 2017). Attwood et al (2017) found a high attrition rate among users after one week of use, however, the app served as a useful tool to facilitate behavioral change among users who were already highly motivated to reduce their alcohol consumption. Unlike the common themes that emerged in Crane et al's (2017) study, the feedback from app users in Attwood et al's (2017) study was more mixed. The one commonality discovered by the authors were users' desire for increased personalized content (Attwood et al, 2017). While Crane et al's (2017) and Attwood et al's (2017) studies were the only ones in the literature that shed light on user 
experiences with specifically alcohol addiction apps, an older study examined user experiences of addiction apps in general.

Savic et al (2013) explored the functions, foci, and user experiences of Smartphone addiction recovery apps. They found the most popular app features among users to include portability and accessibility of the apps, user-friendliness, no cost to use, multiple functionalities, discreet when using, private, and confidential. The app features that users disliked included: technical glitches or technical problems, lack of user-friendliness, and the app being too expensive (Savic et. al, 2013). Both Crane et al's (2017) and Savic et al's (2013) studies uncovered the most important features to new and existing users of alcohol reduction and addiction recovery apps.

Although there were other studies that evaluated user experiences with mHealth apps to assist with other addictions, such as a study by Monney, Penzenstadler, Dupraz, Etter, and Khazaal (2015) that evaluated users' satisfaction and perceived usefulness of a cannabis reduction app, a gap in the literature remained. There was an absence of studies that investigated the acceptance and adoption of alcohol addiction apps in particular, and of addiction apps in general. Thus, the broader literature was examined for the acceptance and adoption of mHealth as it pertains to mental health.

\section{mHealth for Mental Health: Acceptance and Adoption}

To understand consumer acceptance of mHealth services for mental health, Schuster, Tossan, and Drennan (2017) conducted a web-based survey study of 482 French adults. The authors compared behavioral intention models to explain this acceptance. Specifically, they 
compared the theory of reasoned action (TRA) and the theory of planned behavior (TPB) with the model of goal-directed behavior (MGB) (Schuster et al, 2017).

The TRA is a general model that predicts actual behavior based on behavioral intention (Schuster et al, 2017). The determinants of behavioral intention are posited to be "attitude" and "subjective norms" (Schuster et al, 2017). Attitude refers to the tendency to evaluate or appraise a behavior favorably or unfavorably, while subjective norms are rooted in the individual's perception of whether individuals who are important to them support or reject the behavior (Schuster et al, 2017). The TPB, on the other hand, is an extension of the TRA (Schuster et al, 2017). It includes the effects of "perceived behavioral control" on behavior that is beyond an individual's complete volitional control (Schuster et al, 2017). Perceived behavioral control is defined as an individual's "perception of the ease or difficulty of performing the behavior of interest" (Schuster et al, 2017, p.117) which includes the individual's beliefs pertaining to their access to the skills, resources, and the opportunities required to perform a behavior (Schuster et al, 2017). Perceived behavioral control is posited to positively influence behavior. Lastly, the MGB is an extension of the TPB (Schuster et al, 2017). It includes goal and affective influences on behavior (Schuster et al, 2017). It posits "desire", defined as "a personal motivation to perform an action" (Schuster et al, 2017, p. 118), to be the closest determinant of behavioral intention (Schuster et al, 2017).

The authors found that the MGB explained more variance in behavioral intention than the TRA and the TPB (Schuster et al, 2017). Moreover, consistent over the three models, they found subjective norms to have the strongest positive relationship with behavioral intention (Schuster et al, 2017). In other words, regardless of which of the three models were used, participants' beliefs that important others in their lives supported the use of mHealth for mental health, was the 
strongest predictor in determining participants' behavioral intention to use them. Attitude, or participants' appraisals, was found to have a weaker negative relationship with intention (Schuster et al, 2017). The constructs that were found to have insignificant relationships with intention were perceived behavioral control, positive anticipated emotions, and negative anticipated emotions (Schuster et al, 2017).

They noted that although their results suggest that the TRA, the TPB, and the MGB can be employed successfully to understand health behavior, they may not provide a comprehensive understanding of consumers' decisions to adopt mHealth services compared to more technologyspecific models such as the Technology Acceptance Model (Schuster et al, 2017). Thus, acceptance models that are more specific to technology, than to behavior, offer more promise in achieving a greater understanding of consumers' mHealth acceptance and adoption.

A study by Becker (2016) applied an extended version of TAM to explain acceptance and intention to use mHealth mental health apps among 125 young adults in Germany. TAM was created to determine the acceptance of new technologies and to predict their future use in organizations (Becker, 2016). According to TAM, two components are theorized to predict the intention to use a new technology—-perceived usefulness and perceived ease of use (Becker, 2016). Perceived usefulness refers to the impact on performance a user expects to receive from using the new technology (Becker, 2016). Perceived ease of use, on the other hand, refers to the expected effort required to use to the system (Becker, 2016). The other constructs Becker (2016) included in the research model were social influence, self-efficacy, trust, and task-technology fit (TTF).

Social influence describes the extent to which "users perceive that their social environment, such as family members, friends, and colleagues, believe the application should be 
used" (Becker, 2016). Self-efficacy was used to refer to the self-dedication that users possess in committing to treatment through mHealth (Becker, 2016). Trust refers to the trust placed in the application's security (Becker, 2016). Lastly, TTF assumes that "people will use technology that fits a task well” (Becker, 2016).

The results of Becker's (2016) study suggested a possible direct impact of trust and selfefficacy on the acceptance and future use of mobile mental health applications. Trust in the application's security played a major role in participants' considerations of using the apps (Becker, 2016). The study also confirmed a significant influence of perceived usefulness on perceived ease of use with participants indicating that they perceived mHealth mental health apps to be useful and easy to use (Becker, 2016). Social influence, however, was found to be insignificant (Becker, 2016). The results of the study also showed that the knowledge of these apps among participants appeared to be low (Becker, 2016). Since Becker's (2016) use of additional constructs were borrowed from other technology acceptance models, this warrants further investigation of the literature to uncover other constructs from other acceptance models that are key contributors to mHealth acceptance and adoption.

A recent systematic literature review investigated the factors affecting mHealth adoption (Kaium, Bao, Alam, Hasan, \& Hoque, 2019). The authors found the most influential factors to be perceived usefulness, perceived ease of use, social influence, subjective norms, self-efficacy, trust, facilitating conditions, technology anxiety, performance expectancy, effort expectancy, cost, attitude, resistance to change, perceived privacy and security, and perceived behavioral control. They found these factors to be consistent with the results of previous studies that applied the unified theory of acceptance and use of technology (UTAUT), extended UTAUT, TAM, and extended TAM, to mHealth adoption (Kaium et al, 2019). This shows that UTAUT and TAM are 
the dominant theoretical models in explaining mHealth adoption. Since UTAUT encompasses

TAM (Venkatesh et al, 2003), UTAUT will be examined further.

\section{THEORETICAL MODEL}

\section{Unified Theory of Acceptance and Use of Technology (UTAUT)}

The Unified Theory of Acceptance and Use of Technology (UTAUT) was created to unify eight prominent and competing models of user acceptance of new informational technologies (ITs) that posits either intention, or usage, or both, as the key dependent variable (Venkatesh et al, 2003).

According to UTAUT, four independent constructs are theorized to be direct determinants of user acceptance and usage behavior: (1) performance expectancy, (2) effort expectancy, (3) social influence, and (4) facilitating conditions (Venkatesh et al, 2003). Performance expectancy is defined as the extent to which an individual believes that using the system will help them to attain gains in job performance (Venkatesh et al, 2003). Effort expectancy is defined as the level of ease associated with system use (Venkatesh et al, 2003). Social influence is defined as the extent to which an individual perceives that important others believe that they should use the new system (Venkatesh et al, 2003). Lastly, facilitating conditions are defined as the extent to which an individual believes there to be an existence of both an organizational, and a technical, infrastructure to support system use (Venkatesh et al, 2003).

UTAUT was designed to predict the individual behavioral intention of employees to use an IT in an organizational context. The theory posits the first three factors-namely,

performance expectancy, effort expectancy, and social influence, as being direct determinants of 
behavioral intention to use an IT, while facilitating conditions and behavioral intention are predicted to determine technology use (Venkatesh et al, 2003). The key moderators in this model are theorized to be gender, age, voluntariness of use, and experience (Venkatesh et al, 2003).

Gender is theorized to moderate the relationships of performance expectancy, effort expectancy, and social influence with behavioral intention, while age is theorized to moderate the relationships of all four constructs (Venkatesh et al, 2003). Gender and age are thought to moderate the relationship between performance expectancy and behavioral intention such that a stronger effect is proposed for men, particularly younger men (Venkatesh et al, 2003). They are thought to moderate the relationship of effort expectancy on behavioral intention such that a stronger effect is proposed for women, particularly younger women, and for social influence such that a stronger effect is also proposed for women, however, older women (Venkatesh et al, 2003). Age is thought to moderate the relationship of facilitating conditions on use behavior such that the effect is proposed to be stronger with older workers (Venkatesh et al, 2003).

The other two moderating variables are "experience" and "voluntariness of use" (Venkatesh et al, 2003). Operationalized by the authors as three levels based on passage of time (post-training when the system was initially available for use; 1 month later; and 3 months later), "experience", is theorized to moderate the relationships of effort expectancy and social influence on behavioral intention, and facilitating conditions on use behavior (Venkatesh et al, 2012). Lastly, "voluntariness of use" is theorized to be a moderating variable as it moderates the relationship of social influence as it influences behavioral intention (Venkatesh et al, 2012). Figure 1 displays the complete UTAUT research model with the moderating relationships. 


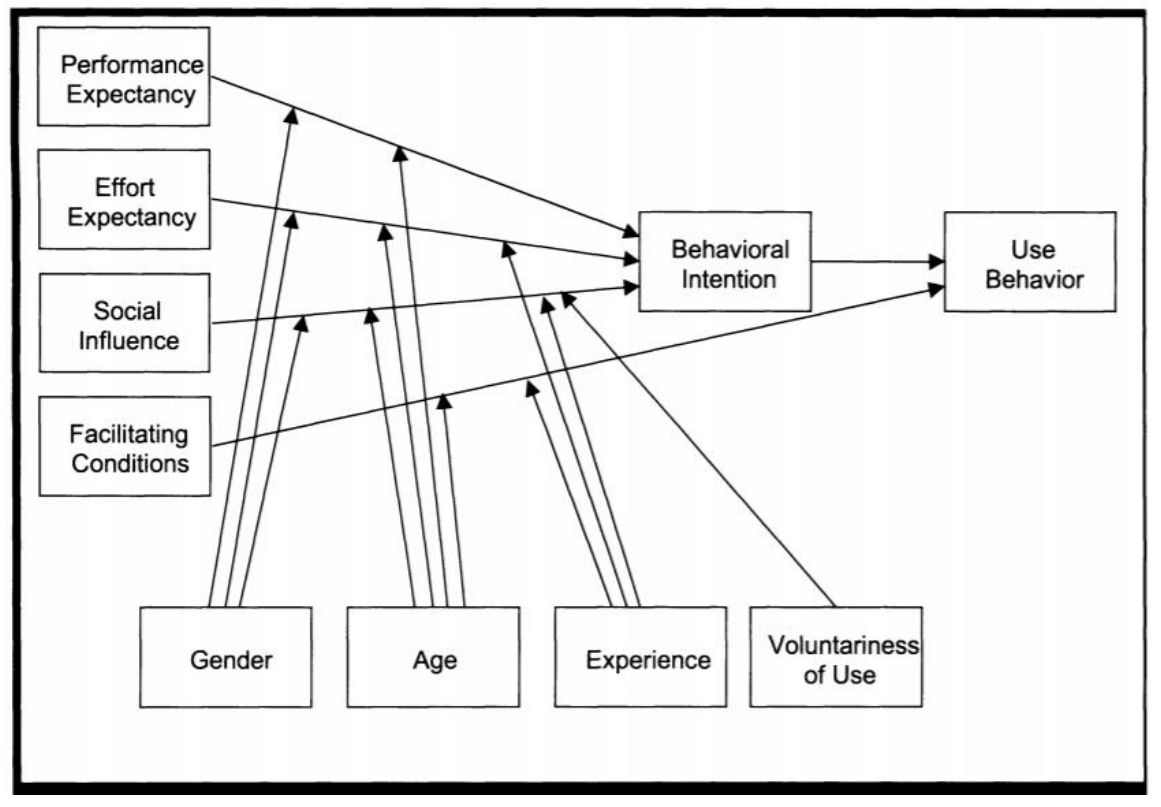

Figure 1. UTAUT Research Model. From "Research Model” by V. Venkatesh, M. Morris, G.

Davis, and F. Davis, 2003. MIS Quarterly, 27(3), 425-478. Retrieved from www.jstor.org/stable/30036540.

After empirically testing the model, the authors found that UTAUT outperformed all the other eight models (which included TRA and TPB) in that it was able to account for $70 \%$ of the variance in individual intention to use an IT while the other models could only account between $17 \%$ and $53 \%$ of variance (Venkatesh et al, 2003). Since its inception, UTAUT has been used as a baseline model and has been applied to study a variety of technologies in organizational and non-organizational settings (Venkatesh, Thong, \& Xu, 2012). Thus, the theoretical framework of UTAUT was chosen to be used in this study due to its comprehensiveness and its superior empirical validity over other competing models.

\section{Unified Theory of Acceptance and Use of Technology (UTAUT2)}

As UTAUT was originally developed to predict technological acceptance and use in an organizational context, the model was extended in the second version to direct it towards a 
consumer use context (Venkatesh et al, 2012). Thus, the operationalizations of the constructs in UTAUT2 are more appropriate as the context of this study also pertains to consumer, and not employee, acceptance and use. The four key constructs, and the moderating variable of experience, have been adapted in UTAUT2 to fit better with the consumer use context (Venkatesh et al, 2012).

In UTAUT2, performance expectancy is "the degree to which using a technology will provide benefits to consumers in performing certain activities" (Venkatesh et al, 2012, p. 159); effort expectancy "is the degree of ease associated with consumers' use of technology" (Venkatesh et al, 2012, p. 159); social influence "is the extent to which consumers perceive that important others (e.g., family and friends) believe they should use a particular technology" (Venkatesh et al, 2012, p. 159); and lastly, facilitating conditions "refer to consumers' perceptions of the resources and support available to perform a behavior" (Venkatesh et al, 2012, p. 159). Just as in the original model, UTAUT2 posits the first three constructs as being direct determinants of behavioral intention to use a technology, which in turn determines (along with facilitating conditions), technology use (Venkatesh et al, 2012).

While UTAUT theorizes the moderating variables to be age, gender, and voluntariness, UTAUT2 drops voluntariness as there is no organizational mandate for consumers to use a technology (Venkatesh et al, 2012). Another modification made to UTAUT in UTAUT2 is the inclusion of additional constructs—namely hedonic motivation and price value which are theorized to be determinants of behavioral intention to use a technology that are moderated by age, gender, and experience, and habit, which is theorized to be both a determinant of behavioral intention and usage of technology (Venkatesh et al, 2012). The authors define hedonic motivation as "the fun or pleasure derived from using a technology" (Venkatesh et al, 2012, p. 
161); price value as “consumers' cognitive tradeoff between the perceived benefits of the applications and the monetary cost for using them" (Venkatesh et al, 2012, p. 161); and habit as "the extent to which an individual believes the behavior to be automatic" (Venkatesh et al, 2012, p. 161). Lastly, experience is retained as a moderating variable in UTAUT2, however, it is operationalized differently as in this version of the model, it is simply defined as "the passage of time from the initial use of a target technology" (Venkatesh et al, 2012, p. 161), thereby omitting the 'levels to use' component that was present in UTAUT's conceptualization of this variable (Venkatesh et al, 2012). It is theorized to moderate the relationship between social influence, hedonic motivation, price value, habit, and the relationship between behavioral intention and use (Venkatesh et al, 2012).

The results from analyzing UTAUT2, showed that when the complete model was analyzed (including its moderating variables), it explained more variance for behavioral intention and for use at $74 \%$ and $52 \%$ respectively, compared to UTAUT's $56 \%$ and $40 \%$ (Venkatesh et al, 2012). This indicates that it is a stronger model than UTAUT in predicting behavioral intention and use under the consumer context.

\section{Applicability and Relevance of UTAUT2 Constructs}

Although UTAUT2 seems more fitting to use in this study as it is directed towards consumer use and has greater explained variance than its predecessor (UTAUT), it had to be modified due to the additional constructs it introduces - namely, the constructs of hedonic motivation, price value, and habit. These constructs were not applicable for this study as Smartphone AUD recovery apps are not necessarily designed to be enjoyable for consumers as they are designed to be effective. Moreover, most Smartphone AUD recovery apps are free on app stores, thus diminishing the importance of the construct of price value as it pertains to this 
study. Lastly, from conversations that took place with directors and managers at addiction treatment facilities in Ontario, many expressed how unlikely it was for their clients to have even heard of such apps to begin with, let alone be using them. Since an initial goal was to recruit most of the respondents from addiction treatment facilities to obtain a higher confidence of AUD sample representativeness, it was decided to proceed with the directors' assumptions on the lack of experience and the lack of habitual use of these apps among their clients. This, then, diminishes the importance of including habit as a construct and of experience as a moderating variable. Thus, the four constructs from the original UTAUT model seem to be most appropriate and relevant to this study, albeit with the operationalizations of those constructs borrowed from UTAUT2. The moderating variable, voluntariness of use, should also be dropped for the reasons outlined by Venkatesh et al (2012) earlier - in the consumer use context, consumers are not mandated to use a technology. It is also important to note here that although there were other constructs from other technology acceptance models, it was a priority to remain faithful to the theoretical model that was chosen for this study, hence the retention of all original UTAUT constructs.

\section{HYPOTHESES AND RESEARCH MODEL}

Performance expectancy has been shown by UTAUT studies to be a strong predictor of behavioral intention to use. Those with AUD will be more likely to have the intention to use AUD apps if they believe that it will help them manage their condition. Therefore,

H1: Performance expectancy is positively correlated with behavioral intention to use AUD apps. 
Studies have also shown the variables of gender and of age to moderate the effect of performance expectancy on behavioral intention. Males have been shown to be highly taskoriented (Venkatesh et al, 2003). This is in line with performance expectancy since the construct pertains to the benefits received by accomplishing certain activities. The construct of performance expectancy, then, will be more important to males. As such, the expectation to receive benefits from AUD recovery apps should be more important for male AUD sufferers. Therefore,

H1(a): Performance expectancy is moderated by gender such that a stronger effect will be observed in men.

Age also plays a moderating role in this relationship since studies have shown that those of younger age tend to place a higher importance on extrinsic rewards (Venkatesh et al, 2003). Consequently, the expectation to receive benefits from AUD recovery apps should be more prominent for younger male AUD sufferers. In this way,

H1(b): Performance expectancy is moderated by age such that there will be a stronger effect in younger men.

UTAUT studies have also shown effort expectancy to be a significant predictor of behavioral intention to use. AUD sufferers will be more likely to want to use Smartphone AUD recovery apps if they believe that they will be easy to use. Therefore,

\section{H2: Effort expectancy is positively correlated with behavioral intention.}

Just as with performance expectancy, studies have shown that the moderating variables of gender and of age play significant moderating roles on the relationship between effort expectancy and behavioral intention. Specifically, expected ease of use has shown to be more important for 
women in contributing to their behavioral intention to use a technology (Venkatesh et al, 2003). Thus, women will be more encouraged to want to use Smartphone AUD recovery apps if they perceive them to be easy to use. Therefore,

H2(a): Effort expectancy will be moderated by gender such that a stronger effect will be observed in women.

Age has also been tied to effort expectancy. Increased age has been associated with difficulties related to the processing of complex stimuli which may be necessary when using a software system (Venkatesh et al, 2003). Thus, those who are younger in age will expect to have an easier time using a technology. Correspondingly, younger women who suffer from AUD will find Smartphone AUD recovery apps easier to use than older women. Therefore,

H2(b): Effort expectancy is moderated by age such that there will be a stronger effect in younger women.

Social influence has also been shown to be a significant predictor of behavioral intention to use a technology. Important others have been demonstrated to play a significant role in an individual's behavioral intention to use. The important others in the lives of an AUD sufferer, then, will significantly influence their individual acceptance of Smartphone AUD recovery apps. As such,

(H3) Social influence is positively correlated with behavioral intention.

Just as with performance expectancy and effort expectancy, the moderating variables of gender and of age also significantly moderate the relationship between social influence on behavioral intention. Studies have shown that women are more sensitive to others' opinions (Venkatesh et al, 2003) thereby rendering them more sensitive to important others' recommendations to use a technology. Women who have AUD, then, will be more sensitive to important others' 
recommendations to use Smartphone AUD recovery apps in deciding their own individual intention to want to use these apps. On this account,

H3(a): Social influence is moderated by gender such that a stronger effect will be observed in women.

Affiliation needs were found to increase with age (Venkatesh et al, 2003). It follows, then, that the intention to use Smartphone AUD recovery apps among older women, in particular, will be strongly shaped by the opinions of important others in their lives. Therefore,

H3(b): Social influence is moderated by age such that there will be a stronger effect in older women.

Several models, from which UTAUT is based upon, posit behavioral intention as being significantly correlated to technology usage. Thus, once an individual forms the intention to use Smartphone AUD recovery apps, this will be correlated to their actual use of these apps. Simply,

H4: Behavioral intention is positively correlated with use behavior.

Lastly, facilitating conditions have been shown to directly precede technology usage. As such, those who believe that they have the resources and the support available to assist with Smartphone AUD recovery app usage, will be more likely to use the apps. Therefore, H5: Facilitating conditions is positively correlated with use behavior.

Age plays a significant moderating role in this relationship. Research has shown that older individuals place more value on the availability of help and support, both on the job (Venkatesh et al, 2003) and in a consumer use context (Venkatesh et al, 2012). Thus, the relationship between the belief in the availability of support and resources to use Smartphone AUD recovery 
apps, and the usage behavior of these apps, will be more pronounced in those who are older. As such,

(H5a) Facilitating conditions will be moderated by age such that a stronger effect will be observed in older individuals.

Since the above hypotheses were based on UTAUT, the research model of this study is identical to that of UTAUT's with the exclusion of the moderating variables, experience and voluntariness of use, which were dropped for reasons outlined in the previous section. Figure 2 shows the research model.

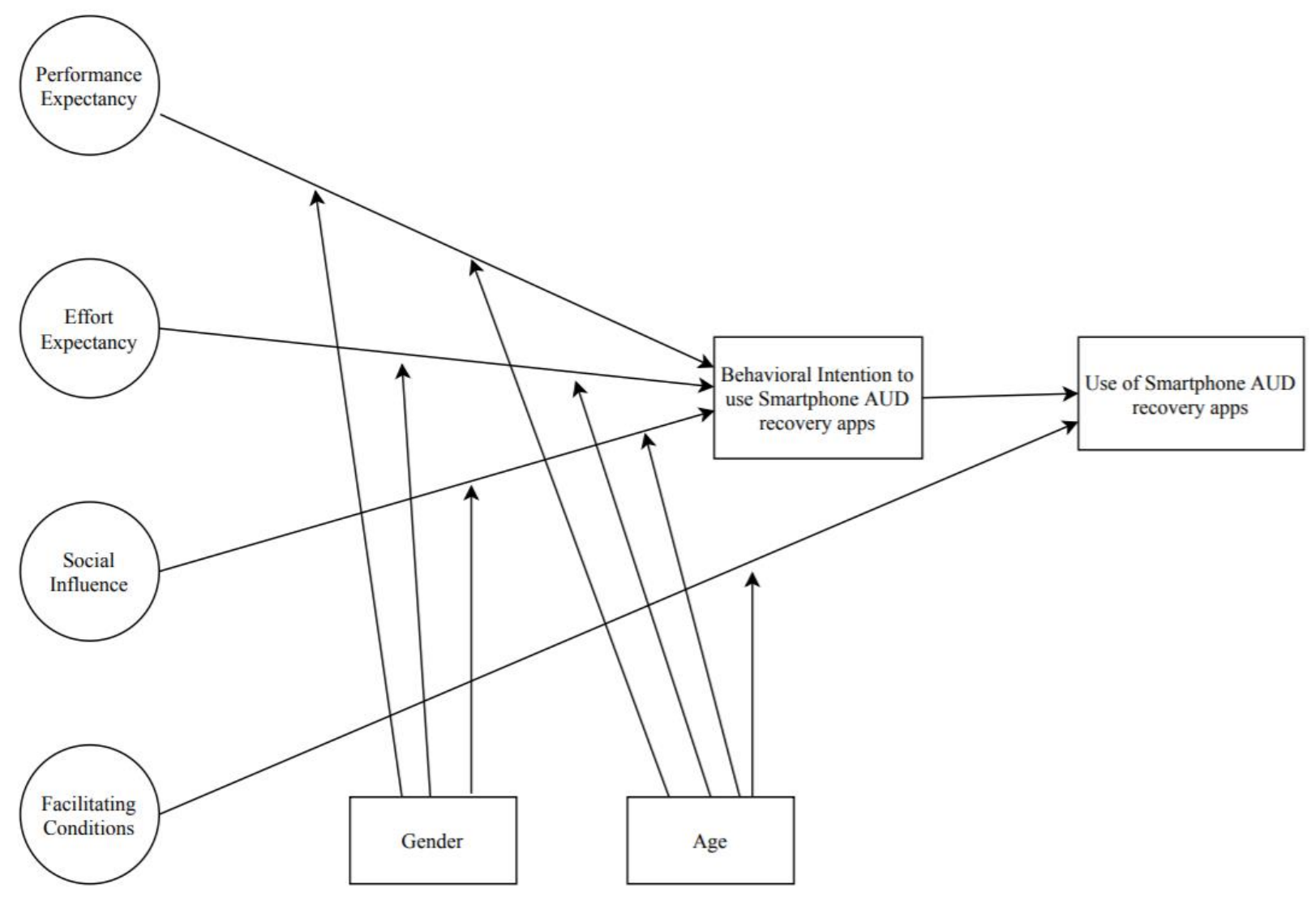

Figure 2. Research Model: Determinants of Behavioral Intention and Usage of Smartphone AUD Recovery Apps. 


\section{METHODOLOGY}

\section{Study Design}

This quantitative, cross-sectional survey study, aimed to recruit a target of 200 adult participants, 18 years of age and older, who self-identified as having an AUD, and who owned a Smartphone. Since human subjects were involved, approval was secured from Ryerson's Research Ethics Board (REB) prior to participant recruitment. From October to November 2019, 160 participants were recruited from six addiction treatment facilities in Ontario and recruited online from various alcohol addiction recovery groups on Facebook. It was decided to recruit from both the addiction treatment facilities and from online as there were not enough respondents recruited from the addiction treatment facilities alone. Therefore, recruitment efforts were expanded to include online means using Facebook AUD recovery support groups which had thousands of members and thus, presented a larger pool of potential respondents to draw from.

The first survey was administered either in-person, in the form of a physical pen-andpaper copy, or online. The online version of the surveys was created using Qualtrics software (Qualtrics, Provo, UT). The setting to “prevent ballot box stuffing” was enabled on Qualtrics. This feature prevents respondents from taking the survey more than once (Qualtrics, n.d.). Moreover, those who took the pen-and-paper version of the survey were not given the online link to the survey. A second follow-up survey was administered (solely online) to the participants one month after they took the first survey.

For in-person recruitment at the addiction treatment facilities, the researcher dropped into workshops that were taking place in which all the respondents were gathered. Prior to the start of 
the workshop, the researcher introduced herself, gave a brief overview of what she was researching, and explained what Smartphone AUD recovery apps were to the clients. The researcher polled the audience to see if anyone had heard of, or used, these apps. For the clients who signaled the affirmative for both, the researcher asked if they would like to share their knowledge of the app they used and the functions that it had, with the rest of their peers. For online recruitment, the researcher provided an explanation of the definition and the functionalities of Smartphone AUD recovery apps in the description of the post that was published with the recruitment flyer attached.

\section{Survey Instrument}

The purpose of the first survey was to investigate the factors contributing to behavioral intention to use Smartphone AUD recovery apps among non-users and existing users of these apps. The purpose of the second, follow-up survey, on the other hand, was to capture subsequent usage behavior from the participants. Particularly, to see whether they ended up using Smartphone AUD recovery apps, the frequency with which they used them, to understand why they used or did not use these apps, and lastly, to measure the same constructs from UTAUT that the previous survey measured. A secondary purpose for the creation of this survey was to measure the reliability and validity of the modified UTAUT questionnaire items. Both the first survey and the follow-up survey used the same adapted UTAUT items with the absence of the screening questions in the follow-up survey. There were no questions on the first survey that the researcher believed would make the participants more inclined to use Smartphone AUD recovery apps. The reader may refer to the Appendix to view the first survey in its entirety.

In order to test the hypotheses, using the framework of UTAUT, the model's questionnaire items were adapted to measure the constructs, particularly its operationalizations 
from UTAUT2. Some questions were dropped while others were modified to fit the context and the target respondents of this study. Table 2 shows a side-by-side comparison between the UTAUT2 questionnaire items' operationalizations of the constructs and the modified operationalizations of the constructs that were used in the questionnaire.

Table 2.

A Comparison of Questionnaire Items Operationalizing UTAUT Constructs

\begin{tabular}{|c|c|c|}
\hline \multirow[t]{2}{*}{ Construct } & \multicolumn{2}{|c|}{ Items } \\
\hline & UTAUT2 & Modified items used in the survey \\
\hline $\begin{array}{l}\text { Performance } \\
\text { Expectancy }\end{array}$ & $\begin{array}{l}\text { I find mobile Internet useful in my daily } \\
\text { life. }\end{array}$ & $\begin{array}{l}\text { I find/would find Smartphone } \\
\text { Alcohol Use Disorder (AUD) } \\
\text { recovery apps useful in } \\
\text { complementing the daily activities I } \\
\text { do to help me recover. } \\
\text { Using Smartphone Alcohol Use } \\
\text { Disorder (AUD) recovery apps } \\
\text { helps/would help me learn recovery } \\
\text { skills more quickly. } \\
\text { Using Smartphone Alcohol Use } \\
\text { Disorder (AUD) recovery apps } \\
\text { helps/would help me increase the } \\
\text { effectiveness of activities I do to } \\
\text { help me recover. }\end{array}$ \\
\hline $\begin{array}{c}\text { Effort } \\
\text { Expectancy }\end{array}$ & $\begin{array}{l}\text { My interaction with mobile Internet is clear } \\
\text { and understandable. } \\
\text { I find mobile Internet easy to use. }\end{array}$ & $\begin{array}{l}\text { Learning how to use Smartphone } \\
\text { Alcohol Use Disorder (AUD) } \\
\text { recovery apps is/would be easy for } \\
\text { me. } \\
\text { My interaction with Smartphone } \\
\text { Alcohol Use Disorder (AUD) } \\
\text { recovery apps is/would be clear and } \\
\text { understandable. }\end{array}$ \\
\hline
\end{tabular}




\begin{tabular}{|c|c|c|}
\hline & $\begin{array}{l}\text { It is easy for me to become skillful at using } \\
\text { mobile Internet. }\end{array}$ & $\begin{array}{l}\text { I find/would find Smartphone } \\
\text { Alcohol Use Disorder (AUD) } \\
\text { recovery apps addiction recovery } \\
\text { apps easy to use. } \\
\text { It is/would be easy for me to } \\
\text { become skillful at using Smartphone } \\
\text { Alcohol Use Disorder (AUD) } \\
\text { recovery apps. }\end{array}$ \\
\hline \multirow{2}{*}{$\begin{array}{c}\text { Social } \\
\text { Influence }\end{array}$} & \multirow[t]{2}{*}{$\begin{array}{l}\text { People who are important to me think that I } \\
\text { should use mobile Internet. }\end{array}$} & $\begin{array}{l}\text { People who are important to me } \\
\text { think that I should use Smartphone } \\
\text { Alcohol Use Disorder (AUD) } \\
\text { recovery apps. } \\
\text { Caregivers think that I should use } \\
\text { Smartphone Alcohol Use Disorder } \\
\text { (AUD) recovery apps. }\end{array}$ \\
\hline & & $\begin{array}{l}\text { People who influence my behavior } \\
\text { think that I should use Smartphone } \\
\text { Alcohol Use Disorder (AUD) } \\
\text { recovery apps. } \\
\text { People whose opinions that I value } \\
\text { prefer that I use Smartphone } \\
\text { Alcohol Use Disorder (AUD) } \\
\text { recovery apps. }\end{array}$ \\
\hline $\begin{array}{l}\text { Facilitating } \\
\text { Conditions }\end{array}$ & $\begin{array}{l}\text { I have the knowledge necessary to use } \\
\text { mobile Internet. }\end{array}$ & $\begin{array}{l}\text { I have the resources necessary to use } \\
\text { Smartphone Alcohol Use Disorder } \\
\text { (AUD) recovery apps. } \\
\text { I have the knowledge necessary to } \\
\text { use Smartphone Alcohol Use } \\
\text { Disorder (AUD) recovery apps. } \\
\text { Smartphone Alcohol Use Disorder } \\
\text { (AUD) recovery apps are } \\
\text { compatible with other technologies I } \\
\text { use. } \\
\text { I can get help from others to use } \\
\text { Smartphone Alcohol Use Disorder } \\
\text { (AUD) recovery apps. }\end{array}$ \\
\hline
\end{tabular}




\begin{tabular}{c|l|l}
\cline { 2 - 3 } $\begin{array}{c}\text { Behavioral } \\
\text { Intention }\end{array}$ & $\begin{array}{l}\text { I intend to continue using mobile internet in } \\
\text { the future. }\end{array}$ & $\begin{array}{l}\text { Do you intend to use or keep using a } \\
\text { Smartphone Alcohol Use Disorder } \\
\text { (AUD) recovery app(s)? }\end{array}$ \\
\hline Use & $\begin{array}{l}\text { Please choose your usage frequency for the } \\
\text { following: a) SMS b) MMS c) Ringtone } \\
\text { and logo download d) Java games } \\
\text { e) Browse websites f) Mobile e-mail }\end{array}$ & $\begin{array}{l}\text { If you are using a Smartphone app } \\
\text { that assists with recovery Alcohol } \\
\text { Use Disorder (AUD), how often do } \\
\text { you use it? }\end{array}$ \\
\hline
\end{tabular}

Note. UTAUT2 questionnaire items from Venkatesh et al (2012).

As seen in Table 2, the questionnaire items in UTAUT2 were specifically geared towards mobile internet and a running assumption from the UTAUT2 questionnaire items was that respondents were already using this technology. Evidently, it was necessary to modify the questions to suit the context of this study and to suit the target respondents - those who selfidentified as having an AUD and who had probably never heard of the existence of Smartphone AUD recovery apps.

Along these lines, a director at one of the addiction treatment facilities from which participants were recruited, advised the researcher to rephrase certain questionnaire items. This was recommended to make it easier to understand for the target respondents. On account of these reasons, care had to be taken to ensure that the survey was not too lengthy, that the questions were not too verbose, and to ensure the absence of sophisticated or heavily technical language. This was done to minimize the loss of attention and of focus from the respondents - many of whom were experiencing attentional deficits.

All UTAUT2 questionnaire items were measured using a seven-point Likert scale ranging from "strongly disagree" to "strongly agree" with age measured in years and gender coded with dummy variables, 0 and 1 , where 0 signified women (Venkatesh et al, 2012). The 
"use" question was also measured using a Likert scale ranging from "never" to "many times a day" (Venkatesh et al, 2012). Once again, to remain faithful to the UTAUT items, the questionnaire items in this study were also measured using Likert scales, however, with some slight differences.

The questionnaire items measuring the UTAUT constructs, apart from the constructs of behavioral intention and of use, were measured using a five-point Likert scale ranging from "strongly disagree" to "strongly agree". The question measuring behavioral intention was measured using a three-point Likert scale ranging from "yes" to "no" and the question measuring use was measured using a six-point Likert scale ranging from "everyday" to "at least once a year". These slight changes to the Likert scales were made for the purposes of brevity and simplicity - to cut down on the content that the respondents would have to process which was also hoped to reduce confusion caused by too many similar-sounding options.

Age was also measured in years, and gender was also coded with dummy variables, however, "1" signified male, "2" signified female, and a third option, "other", coded with "3", was given for respondents who did not identify with the first two. Additionally, screening questions to ensure that participants met the eligibility criteria of self-identifying as having an AUD, and of owning a Smartphone, were asked at the very beginning of the first survey. The first question of the first survey asked participants,

Is your level of alcohol consumption concerning to you? Here is the technical term and definition of Alcohol Use Disorder (AUD), defined as "a chronic and relapsing brain disease characterized by compulsive alcohol use, loss of control over alcohol intake, and a negative emotional state when not using"? How much does this definition sound like you? (NIAAA, 2014). 
This question was measured using a three-point Likert scale ranging from "not at all like me" to "very much like me". Results from participants who answered "not at all like me" were not included in data analysis and were not able to proceed with the rest of the survey if they took the online version.

The second question on the first survey, which was the second screening question, asked the participants whether they owned a Smartphone. Participants were to indicate a "yes" or "no". Those who indicated the latter were also excluded from data analysis and were also not able to proceed with the rest of the survey, if they took the online version. Lastly, a few open-ended questions were included in both the first survey and the follow-up survey to inquire about why participants did or did not use Smartphone AUD recovery apps, and what would make them want to use such apps.

\section{Follow-up Survey Results}

The second, follow-up survey, suffered from a low participant response rate. While there were 59 valid responses from the first survey, after using the same survey quality procedures to extract valid responses from those of the 59 individuals who participated in the follow-up survey, only 28 valid responses remained. This is too small of a sample size for meaningful statistical tests to be conducted, therefore, the responses from the follow-up survey were not used.

\section{Data Analysis}

The results of the survey were analyzed using IBM/SPSS Statistics (version 26) and SmartPLS 3 (version 3.2.9). SPSS Statistics was used to extract descriptive statistics, to calculate frequencies, graphically represent the data, and to perform Chi-square tests to test the associations between variables. Most of the tables and graphs under "descriptive statistics" were 
taken directly from SPSS while the remaining were formatted on Microsoft Excel. Since the focus of this study was on identifying the antecedents of Smartphone AUD recovery app adoption, there were no exclusion criteria in place to exempt the responses of those who did not possess prior knowledge about the existence of these apps. Therefore, data analysis was conducted on all 59 valid survey responses.

\section{Testing the Theoretical Model}

Partial least squares (PLS), a type of structural equation modelling (SEM), was used to test the model based on its capabilities of testing the many interaction terms that are present in UTAUT (Venkatesh et al, 2012). PLS-SEM was used also because it works efficiently with small sample sizes and complex models, makes little to no assumptions about the underlying data and makes no distributional assumptions (it is non-parametric) (Hair, Hult, Ringle, \& Sarstedt, 2017). Moreover, it "can easily handle reflective and formative measurement models, as well as single-item constructs," without returning identification problems (Hair et al 2017).

A primary goal of using PLS-SEM is to maximize the explained variance of the endogenous latent variables within the PLS path model (Hair et al, 2017). On account of this, the quality of the PLS-SEM measurement and structural models must be evaluated (Hair et al, 2017). The quality is shown using certain metrics that indicate the model's predictive capabilities (Hair et al, 2017). Thus, in PLS-SEM, two analyses take place. First, the measurement model is evaluated using metrics to assess reliability, convergent validity, and discriminant validity of constructs (Hair et al, 2017). Second, the structural model is evaluated using metrics such as, the coefficient of determination $\left(\mathrm{R}^{2}\right)$, and using other metrics to assess the size and the statistical significance of the structural path coefficients (Hair et al, 2017). 
The SmartPLS 3 software, which employs PLS-SEM, was used to test the theoretical model. First, the measurement model was assessed for its reliability, convergent validity, and discriminant validity of constructs. The metrics used to assess reliability were Cronbach's alpha and composite reliability (CR). Convergent validity was assessed using indicator reliability (outer loadings) and average variance extracted (AVE). Discriminant validity was assessed using the Heterotrait Monotrait (HTMT) ratio. Lastly, the structural model was assessed using $\mathrm{R}^{2}$ and bootstrapping tests were conducted to examine the statistical significance of the $\mathrm{R}^{2}$ values and of the path coefficients.

\section{RESULTS}

\section{Descriptive Statistics}

Although 160 participants took part in the first survey of the study, after filtering out respondents who: did not meet the eligibility criteria (i.e. indicated that they did not at all identify with the definition of AUD, did not own a Smartphone) or failed to pass the survey

quality criteria, the responses of 59 individuals remained. The 59 respondents were comprised of 40 males $(67.8 \%), 17(28.8 \%)$ females, and 2 (3.4\%) individuals who identified as “other" gender. The average age of the respondent was $36(\mathrm{SD}=10.3)$ years of age, with the youngest being 19 years and the oldest being 65 years of age. Further, slightly more respondents $(n=35$; $59.3 \%)$ took the pen-and-paper version of the survey compared to the online version $(n=24$; $40.7 \%)$.

It is important to note that most of the survey responses which had to be discarded due to quality issues were from the respondents who took the survey online. A breakdown summary of the dropped respondents is illustrated in Table 3. 
Table 3 .

Breakdown of Dropped Respondents

\begin{tabular}{|c|c|c|c|}
\hline Survey Quality Issues & Specific Quality Issue(s) & No. of Respondents & No. of Respondents Remaining \\
\hline Missing Contact Information \& Consent & $\begin{array}{l}\text { Did not provide both contact information to } \\
\text { receive incentive and their consent to } \\
\text { participate in the follow-up survey }\end{array}$ & 2 & 158 \\
\hline \multirow{3}{*}{ Self-identification with AUD } & $\begin{array}{l}\text { Lack of self-identification with the } \\
\text { definition of AUD (selected "Not at all like } \\
\text { me") }\end{array}$ & 4 & 154 \\
\hline & Did not provide an answer to this question & 2 & 152 \\
\hline & $\begin{array}{l}\text { Chose not to answer this question (selected } \\
\text { "Prefer not to answer") }\end{array}$ & 1 & 151 \\
\hline Smartphone Ownership & Did not own a Smartphone & 2 & 149 \\
\hline Completion Time & $<5$ minutes & 23 & 126 \\
\hline Response Contradictions & $\begin{array}{l}\text { i.e. indicated that they had not heard of the } \\
\text { existence of Smartphone AUD recovery } \\
\operatorname{app}(\mathrm{s}) \text { prior to the survey yet answered in } \\
\text { the positive when asked if they had ever } \\
\text { used these apps }\end{array}$ & 15 & 111 \\
\hline \multirow{2}{*}{$\begin{array}{l}\text { Taken Multiple Times by the Same } \\
\text { Person/Group of People }\end{array}$} & Same Internet Protocol (IP) address & 29 & 82 \\
\hline & $\begin{array}{l}\text { Highly similar responses to the open-ended } \\
\text { questions and to the UTAUT scale items }\end{array}$ & 16 & 66 \\
\hline $\begin{array}{c}\text { Response Incoherency in the Open-ended } \\
\text { Questions }\end{array}$ & i.e. did not address the question & 5 & 61 \\
\hline Lack of Answers to UTAUT Scale Items & $\begin{array}{l}\text { Gave "Undecided" as a response to most of } \\
\text { the items }\end{array}$ & 2 & 59 \\
\hline
\end{tabular}

As seen in Table 3, the quality issues observed in this survey included: an extremely short survey completion time, many questions left unanswered, contradictions in responses, survey taken multiple times by the same individual or the same group of individuals (as indicated by the (IP) address or repetitions in the open-ended question responses). Although the "prevent ballot box stuffing" feature was enabled on Qualtrics to prevent respondents from taking the survey more than once, this feature is not entirely infallible. The more tech-savvy respondents could have circumvented this feature by clearing their cookies, switching to a different web browser, or 
using a different device (Qualtrics, n.d.). Evidently, this was a major problem that was encountered in this study that led to the disqualification of many online respondents.

Turning to the gender profile of the sample in this study, the overrepresentation of males $(67.8 \%)$ was very much like the overrepresentation of males in the Statistics Canada 2018 report of heavy drinkers (60.8\% of males compared to $39.2 \%$ of females). The distribution of the ages of respondents in the Statistics Canada report compared to the ages of respondents who took part in this study, is illustrated in Figure 3 and organized by age group.

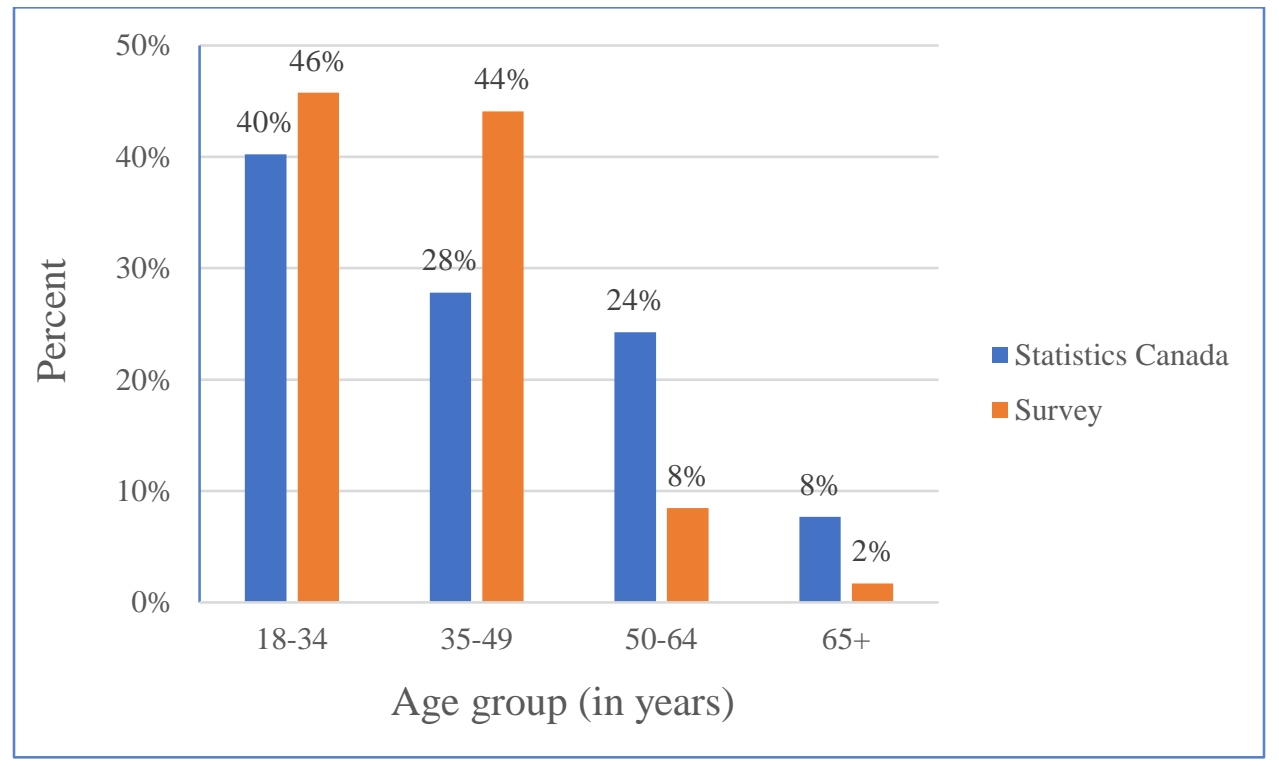

Figure 3. Comparison of the Age Groups of Respondents in the Statistics Canada Population and in the Survey Sample. Note. Statistics Canada age data from Statistics Canada (2018)

From Figure 3, similarities are shown in the percentages of the respondents for each of the age groups, with the smallest difference being $6 \%$ and the largest difference being $16 \%$. Both groups also had the highest number of respondents in the 18-34 years of age category, with the lowest number of respondents in the $65+$ years of age category. Taken together with the similar 
gender distributions described earlier, it can be concluded that the sample in this study seems to be representative of the population of heavy drinkers in Canada.

Most respondents identified strongly with the definition of AUD ( $n=45 ; 76.3 \%)$, stating that the definition sounded "very much like" them while the remaining respondents $(n=14$; 23.7\%), stated that the definition of AUD sounded "somewhat like" them. Given the higher proportion of respondents who identified strongly with the definition of AUD, it would be useful to examine any differences in the average responses of this group of participants compared to those who only partially identified with the definition of AUD - particularly when it comes to the UTAUT questionnaire items. Table 4 lists the average scores of these two groups on the UTAUT constructs which, once again, were measured using a 5-point Likert scale for performance expectancy, effort expectancy, social influence, and facilitating conditions, a 3point scale for behavioral intention, and a six-point scale to measure use behavior. Table 4 also lists the average technology acceptance score which was calculated by summing up the averages on each of the items for all the constructs.

Table 4.

Level of Identification with AUD and Participants' Mean Scores on UTAUT Constructs

\begin{tabular}{|c|c|c|}
\hline & \multicolumn{2}{|c|}{ Level of Identification with AUD } \\
\hline UTAUT constructs & $\begin{array}{c}\text { "Somewhat like } \\
\text { me" }(\mathbf{n}=14)\end{array}$ & $\begin{array}{c}\text { "Very much like } \\
\text { me" }(n=45)\end{array}$ \\
\hline Performance expectancy (3 items) & 11.64 & 11.88 \\
\hline Effort expectancy (4 items) & 15.55 & 16.78 \\
\hline Social influence (4 items) & 13.57 & 9.65 \\
\hline Facilitating conditions (4 items) & 16.08 & 15.03 \\
\hline Behavioral intention (1 item) & 2.71 & 2.80 \\
\hline Use behavior (1 item) & 3.50 & 3.18 \\
\hline Total mean score & 63.05 & $\mathbf{5 9 . 3 2}$ \\
\hline
\end{tabular}


From Table 4, those who partially identified with having an AUD, had a higher overall score (63.05) on technology acceptance and usage than those who strongly identified as having an AUD (59.32). Although the "somewhat like me" group had a higher overall score, the individual mean scores for each of the UTAUT constructs was lower than the "very much like me" group, except for higher mean scores on the constructs of social influence, facilitating conditions, and use behavior. Those in the "very much like me" group had higher mean scores on the constructs of performance expectancy, effort expectancy, and behavioral intention. The construct with the largest difference in mean scores between the two groups was the construct of social influence with a 3.92-point difference-13.57 and 9.65 respectively, between the "somewhat like me" and "very much like me" groups.

The above results show that those who only partially identify with having an AUD may demonstrate slightly higher technology acceptance and usage of Smartphone AUD recovery apps compared to those who strongly identify with having an AUD. Moreover, the former group may be more sensitive to social influencing factors in deciding their behavioral intention to use these apps compared to those in the latter group who appear to be less sensitive to social influencing factors.

The 35 respondents who took the pen-and-paper version of the survey were recruited directly from addiction treatment facilities. Thus, it is worth investigating whether there were any differences in the level of self-identification with the definition of AUD between the participants who were recruited from the facilities compared to the participants who were recruited from social media. The "somewhat like me" level of identification with AUD was coded with "2" while the "very much like me" level of identification was coded with "3". 
Conversely, the "pen-and-paper" version of the survey was coded with "1" while the "online" version was coded with "2".

Figure 4 illustrates the levels of self-identification with AUD by survey version. Table 5 lists the average version of the survey taken by respondents in each level of self-identification with AUD. Table 6 displays the results from an independent samples t-test that was conducted to identify any statistically significant mean differences between the two unrelated groups.

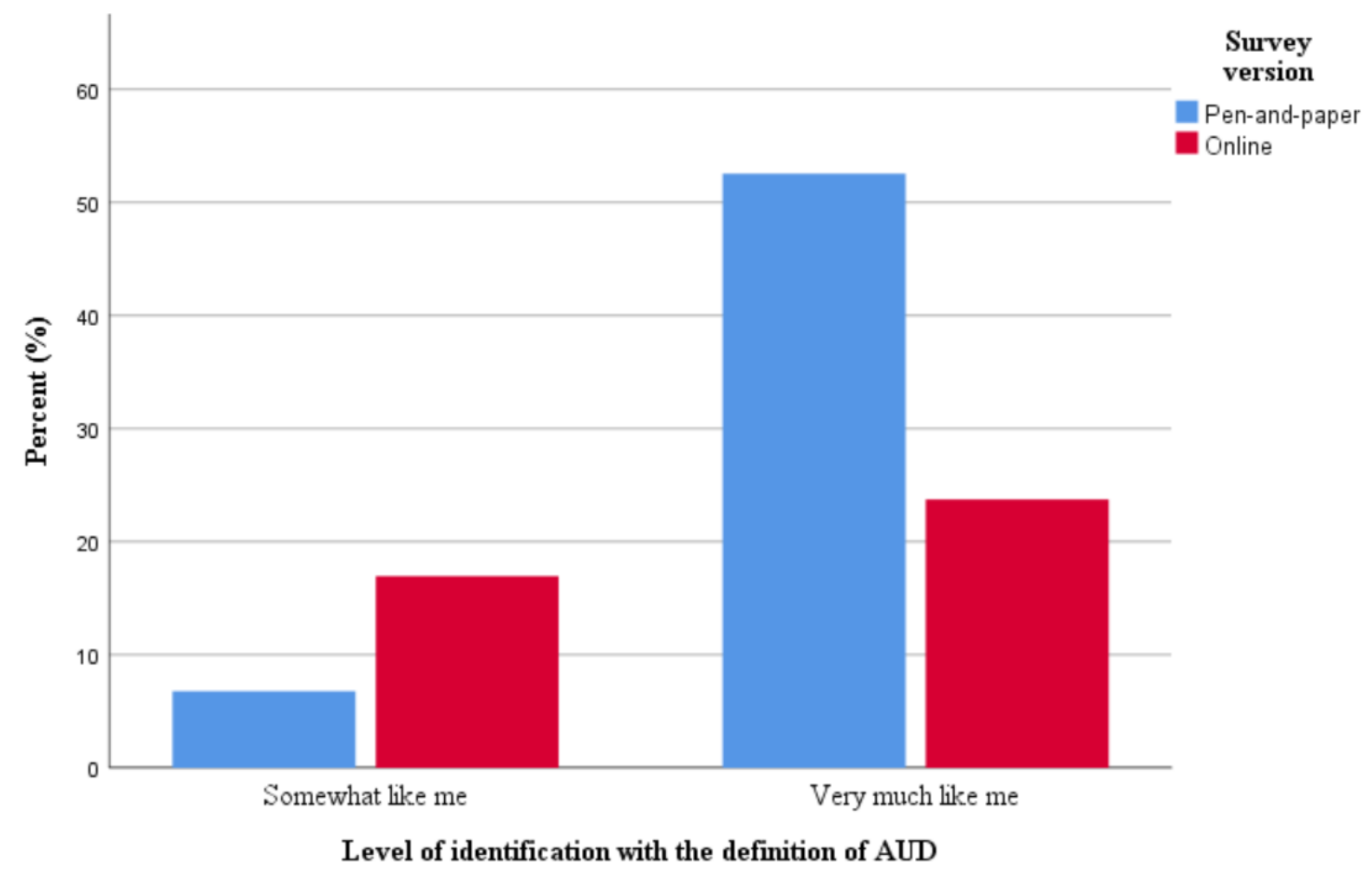

Figure 4. Survey Version and Self-identification with AUD

Table 5.

Group Statistics: Level of Identification with the Definition of AUD and Survey Version 


\begin{tabular}{ll|r|r|r} 
& $\begin{array}{l}\text { Level of identification with } \\
\text { the definition of AUD }\end{array}$ & N & Mean & Std. Deviation \\
\hline Survey version & Somewhat like me & 14 & 1.71 & .469 \\
\cline { 2 - 5 } & Very much like me & 45 & 1.31 & .468 \\
\hline
\end{tabular}

Table 6

Independent Samples t-test: Level of Identification with AUD by Survey Version

\begin{tabular}{|c|c|c|c|c|c|c|c|}
\hline & \multicolumn{7}{|c|}{ t-test for Equality of Means } \\
\hline & \multirow[b]{2}{*}{$\mathrm{t}$} & \multirow[b]{2}{*}{ df } & \multirow{2}{*}{$\begin{array}{l}\text { Sig. (2- } \\
\text { tailed) }\end{array}$} & \multirow{2}{*}{$\begin{array}{c}\text { Mean } \\
\text { Difference }\end{array}$} & \multirow{2}{*}{$\begin{array}{l}\text { Std. Error } \\
\text { Difference }\end{array}$} & \multicolumn{2}{|c|}{$\begin{array}{l}95 \% \text { Confidence Interval of } \\
\text { the Difference }\end{array}$} \\
\hline & & & & & & Lower & Upper \\
\hline Survey version & 2.813 & 57 & .007 & .403 & .143 & .116 & .690 \\
\hline
\end{tabular}

Note. Statistical significance: $* \mathrm{p}<0.05 ; * * \mathrm{p}<0.01 ; * * * \mathrm{p}<0.001$

Figure 4 shows that far more respondents who took the pen-and-paper version of the survey identified strongly with the definition of AUD $(n=31,52.5 \%)$ than those who only partially identified $(n=4,6.8 \%)$. This is reflected in the group statistics from Table 5 which shows that the mean score for participants in the "very much like me" group was $1.31 \pm 0.47$ points, indicating that most of them took the pen-and-paper version of the survey.

This was not the case for the respondents who took the online version of the survey. They were more equally segregated in both levels of self-identification with the definition of AUD, although slightly more respondents strongly identified $(n=14,23.7 \%)$ than partially identified ( $\mathrm{n}$ $=10,16.9 \%)$. As such, the group statistics in Table 5 show that the mean survey score for the respondents in the "somewhat like me" group was $1.71 \pm 0.47$ points, indicating that most of them took the online version of the survey. 
The results from the independent samples t-test in Table 6 show that there was a mean difference of 0.40 (95\% CI, 0.12 to 0.69 ) points in the survey version score between the groups, $t$ $(57)=2.81, p=0.007$. These results demonstrate high statistical significance. The null hypothesis, therefore, is to be rejected - there seems to be a positive association between participants' level of self-identification with AUD and the survey version they took.

Lastly, several questions were asked in the beginning of the survey to capture both participants' knowledge of the existence of Smartphone AUD recovery apps, and existing users of these apps. Table 7 lists these questions.

Table 7.

Questions to Investigate Participants' Knowledge of Smartphone AUD Recovery Apps and their Use History

\begin{tabular}{|c|l|}
\hline Question No. & \multicolumn{1}{|c|}{ Question } \\
\hline $\mathbf{3}$ & $\begin{array}{l}\text { Before taking this survey, were you aware of the existence of Smartphone apps } \\
\text { that can be used to help with (not substitute) recovery from Alcohol Use Disorder } \\
\text { (AUD)? }\end{array}$ \\
\hline $\mathbf{4}$ & $\begin{array}{l}\text { Have you ever used a Smartphone app for recovering from Alcohol Use Disorder } \\
\text { (AUD)? }\end{array}$ \\
\hline $\mathbf{7}$ & $\begin{array}{l}\text { Are you currently using a Smartphone app to help you recover from Alcohol Use } \\
\text { Disorder (AUD)? }\end{array}$ \\
\hline $\mathbf{9}$ & $\begin{array}{l}\text { If you are using a Smartphone app that assists with recovery Alcohol Use Disorder } \\
\text { (AUD), how often do you use it? }\end{array}$ \\
\hline
\end{tabular}

Questions 3, 4, and 7 were closed-ended using a simple "yes/no" answer format while question 9, the single-item measure used to capture usage behavior as part of UTAUT, was answered using a 6-point Likert scale ranging from "Never" to "Everyday". The results from question 9 
will be further analyzed in the next subsection which evaluates the theoretical model using PLSSEM.

The responses from question 3 showed that most participants $(n=42,71.2 \%)$ had prior awareness of the existence of Smartphone AUD recovery apps, while the minority of participants ( $\mathrm{n}=17,28.8 \%$ ) did not. Of the participants who knew of the existence of these apps beforehand, $19(32.2 \%)$ were from the pen-and-paper sample, while $23(39.0 \%)$ were from the online sample. Of the participants who stated that they had no such prior knowledge, $16(27.1 \%)$ were from the pen-and-paper sample and only $1(0.02 \%)$ was from the online sample. This highlights a difference between the two survey versions. Almost all respondents who took the online version of the survey $(95.8 \%)$ possessed this prior knowledge compared to only slightly more than half of the pen-and-paper respondents $(54.3 \%)$ who had this prior knowledge.

This warrants further investigation to examine whether there were also differences in the average technology acceptance between the group who possessed prior knowledge of the existence of Smartphone AUD recovery apps and the group who did not possess this prior knowledge. The mean scores for the UTAUT constructs were calculated and totaled to yield the mean technology acceptance score between both groups. These scores are illustrated in Table 8 . Table 8 .

Prior Awareness of the Existence of Smartphone AUD Recovery Apps and Participants' Mean Scores on UTAUT Constructs

\begin{tabular}{c|c}
\hline & $\begin{array}{c}\text { Prior Awareness of the Existence of } \\
\text { Smartphone AUD Recovery Apps }\end{array}$ \\
\hline \hline UTAUT Constructs & Yes $(\mathbf{n}=42) \quad$ No $(\mathrm{n}=17)$ \\
\hline
\end{tabular}




\begin{tabular}{l|rr} 
Performance Expectancy (3 items) & 12.00 & 11.33 \\
Effort Expectancy (4 items) & 17.12 & 14.92 \\
Social Influence (4 items) & 14.60 & 12.67 \\
Facilitating Conditions (4 items) & 17.19 & 16.64 \\
Behavioral Intention (1 item) & 2.83 & 2.65 \\
Use Behavior (1 item) & 4.17 & 1.00 \\
\hline Total mean score & $\mathbf{6 7 . 9 1}$ & $\mathbf{5 9 . 2 1}$ \\
\hline \hline
\end{tabular}

As seen in Table 8, there was a difference in the overall technology acceptance between both groups. The group who had heard of the existence of Smartphone AUD recovery apps showed more technology acceptance (67.91) than the group who had not heard of the existence of these apps (59.21). The group with the prior knowledge of the apps also scored higher on each of the UTAUT constructs. Thus, to analyze if the difference in technology acceptance between both groups was statistically meaningful, an independent samples t-test was conducted on each item for all the UTAUT constructs, as shown in Table 10, while the group statistics for each UTAUT item are shown in Table 9.

Table 9.

Group Statistics: Prior Awareness of the Existence of Smartphone AUD Recovery Apps and Mean Scores on UTAUT Questionnaire Items. 


\begin{tabular}{|c|c|c|c|c|c|}
\hline & & \multicolumn{4}{|c|}{$\begin{array}{c}\text { Prior Awareness of the Existence of Smartphone } \\
\text { AUD Recovery Apps }\end{array}$} \\
\hline \multirow[b]{2}{*}{ UTAUT Constructs } & \multirow[b]{2}{*}{ UTAUT Items } & \multicolumn{2}{|c|}{ Yes $(n=42)$} & \multicolumn{2}{|c|}{ No $(n=17)$} \\
\hline & & Mean & Std. Deviation & Mean & Std. Deviation \\
\hline \multirow{3}{*}{ Performance Expectancy } & PE1 & 4.07 & .905 & 4.00 & .845 \\
\hline & PE2 & 3.90 & 1.008 & 3.65 & .702 \\
\hline & PE3 & 4.02 & 1.024 & 3.69 & .479 \\
\hline \multirow{4}{*}{ Effort Expectancy } & EE1 & 4.36 & .618 & 3.94 & 1.289 \\
\hline & EE2 & 4.21 & .645 & 3.63 & 1.025 \\
\hline & EE3 & 4.19 & .862 & 3.41 & 1.004 \\
\hline & EE4 & 4.36 & .577 & 3.94 & .827 \\
\hline \multirow{4}{*}{ Social Influence } & SI1 & 3.74 & 1.191 & 3.12 & .781 \\
\hline & SI2 & 3.62 & .941 & 3.31 & .883 \\
\hline & SI3 & 3.57 & 1.119 & 3.18 & .680 \\
\hline & SI4 & 3.67 & 1.081 & 3.06 & .946 \\
\hline \multirow{4}{*}{ Facilitating Conditions } & FC1 & 4.52 & .634 & 4.35 & .786 \\
\hline & FC2 & 4.40 & .587 & 4.12 & 1.054 \\
\hline & FC3 & 4.24 & .656 & 3.94 & .854 \\
\hline & FC4 & 4.02 & .924 & 4.24 & .664 \\
\hline Behavioral Intention & BI & 2.83 & .437 & 2.65 & .702 \\
\hline Use Behavior & UB & 4.17 & 2.695 & 1.00 & .000 \\
\hline
\end{tabular}

Table 10.

Independent Samples t-test: Prior Awareness of the Existence of Smartphone AUD Recovery Apps and Mean Scores on UTAUT Questionnaire Items

\begin{tabular}{|c|c|c|c|c|c|c|c|c|}
\hline \multirow[b]{3}{*}{ UTAUT Constructs } & \multirow[b]{3}{*}{ UTAUT items } & \multicolumn{7}{|c|}{ t-test for Equality of Means } \\
\hline & & \multirow[b]{2}{*}{$\mathbf{t}$} & \multirow[b]{2}{*}{ df } & \multirow[b]{2}{*}{$\begin{array}{l}\text { Sig. (2- } \\
\text { tailed) }\end{array}$} & \multirow[b]{2}{*}{\begin{tabular}{c|} 
Mean \\
Difference
\end{tabular}} & \multirow[b]{2}{*}{$\begin{array}{l}\text { Std. Error } \\
\text { Difference }\end{array}$} & \multicolumn{2}{|c|}{$\begin{array}{l}\text { 95\% Confidence } \\
\text { Interval of the } \\
\text { Difference }\end{array}$} \\
\hline & & & & & & & Lower & Upper \\
\hline \multirow{3}{*}{ Performance Expectancy } & PE1 & .272 & 54 & .786 & .073 & .269 & -.465 & .612 \\
\hline & PE2 & .962 & 57 & .340 & .258 & .268 & -.279 & .794 \\
\hline & PE3 & 1.257 & 56 & .214 & .336 & .267 & -.199 & .872 \\
\hline \multirow{4}{*}{ Effort Expectancy } & EE1 & 1.678 & 56 & .099 & .420 & .250 & -.081 & .921 \\
\hline & EE2 & $2.62 *$ & 56 & .011 & .589 & .225 & .139 & 1.040 \\
\hline & EE3 & $2.996 * *$ & 57 & .004 & .779 & .260 & .258 & 1.299 \\
\hline & EE4 & $2.203 *$ & 57 & .032 & .416 & .189 & .038 & .794 \\
\hline \multirow{4}{*}{ Social Influence } & SI1 & 1.978 & 57 & .053 & .620 & .314 & -.008 & 1.249 \\
\hline & SI2 & 1.486 & 57 & .143 & .395 & .266 & -.137 & .927 \\
\hline & SI3 & $2.016^{*}$ & 56 & .049 & .604 & .300 & .004 & 1.205 \\
\hline & SI4 & .997 & 56 & .323 & .307 & .307 & -.309 & .923 \\
\hline \multirow{4}{*}{ Facilitating Conditions } & FC1 & .874 & 57 & .386 & .171 & .195 & -.221 & .562 \\
\hline & FC2 & 1.335 & 57 & .187 & .287 & .215 & -.143 & .718 \\
\hline & FC3 & 1.433 & 56 & .157 & .301 & .210 & -.120 & .721 \\
\hline & FC4 & -.857 & 57 & .395 & -.211 & .247 & -.706 & .283 \\
\hline Behavioral Intention & BI & 1.234 & 57 & .222 & .186 & .151 & -.116 & .489 \\
\hline Use Behavior & UB & $4.819 * * *$ & 57 & .000 & 3.167 & .657 & 1.851 & 4.482 \\
\hline
\end{tabular}


Note. Statistical significance: ${ }^{*} \mathrm{p}<0.05 ; * * \mathrm{p}<0.01 ; * * * \mathrm{p}<0.001$

From Table 10, there were largely no statistically significant differences between the two groups on the UTAUT items (12 out of 17 items). There were, however, statistically significant differences between the groups on most of the items for effort expectancy (EE2, EE3, and EE4), one item for social influence (SI3), and on the single-item measure for use behavior (UB). In conjunction with the mean scores for these items in Table 9, these results indicate that those who had prior knowledge of the existence of Smartphone AUD recovery apps were more likely to find them easy to use and were more sensitive to the opinions of people they valued, in shaping their own decision to want to use these apps. As regards use behavior, those who have never heard of these apps correspondingly indicated that they had never used them-hence the extremely high statistical significance for use behavior. While these results bring to light some differences in the technology acceptance of both groups, it is important to call attention to the large discrepancy in the number of respondents for both groups - 42 respondents in the "yes" condition, and only 17 respondents in the "no" condition. This discrepancy could potentially explain the differences in technology acceptance between both groups.

From the responses to the subsequent questions in Table 7, the differences between the online survey version group and the pen-and-paper survey version group continued for other variables. Those in the online sample demonstrated a markedly increased likelihood of having heard of, used, and continuing to use Smartphone AUD recovery apps. Although slightly more than half of the participants $(n=32,54.2 \%)$ had used these apps in the past, with the remaining 27 participants $(45.8 \%)$ having never used these apps, 21 of those 32 participants (35.6\%) were from the online sample compared to 11 (18.6\%) from the pen-and-paper sample. Meanwhile, only 3 participants from the online sample had never used AUD recovery apps compared to 24 
participants in the pen-and-paper sample who had never used these apps. Thus, most of the participants in the online sample (87.5\%) used AUD recovery apps in the past, while most participants in the pen-and-paper sample (68.6\%) had never used these apps.

For question 7 , less than half of the participants $(n=26,44.1 \%)$ stated that they were current users of these apps while more than half $(n=33,55.9 \%)$ stated that they were not currently using these apps. Of the 26 current app users, 19 (32.2\%) were from the online sample with only 7 (11.9\%) from the pen-and-paper sample. Of the 33 non-users, 28 (47.5\%) were from the pen-and-paper sample while only $5(0.08 \%)$ were from the online sample. Evidently, most of the participants from the pen-and-paper sample (80.0\%) do not currently use these apps whereas most of the participants from the online sample (79.2\%) were current AUD recovery app users.

Pertaining to Smartphone AUD recovery app usage frequency, it was found that 34 participants (57.6\%) never use these apps, $3(5.1 \%)$ stated that they used them "at least once a month", $11(18.6 \%)$ stated that they used them "at least once a week", and the remaining 11 participants (18.6\%) stated that they used them "at least once a day". Of the 34 participants who stated that they never use AUD recovery apps, 29 (49.2\%) were from the pen-and-paper sample and $5(8.5 \%)$ were from the online sample. Of the 3 participants who used them at least once a month, $2(3.4 \%)$ were from the online sample and $1(1.7 \%)$ was from the pen-and-paper sample. Of the 11 who stated that they used the apps at least once a week, $8(13.6 \%)$ were from the online sample and $3(5.1 \%)$ were from the pen-and-paper sample. Lastly, from the 11 participants who stated that they used these apps everyday, $9(15.3 \%)$ were from the online sample and $2(3.4 \%)$ were from the pen-and-paper sample. Figure 5 illustrates this distribution of total usage frequency of Smartphone AUD recovery apps and groups the data by survey version. 


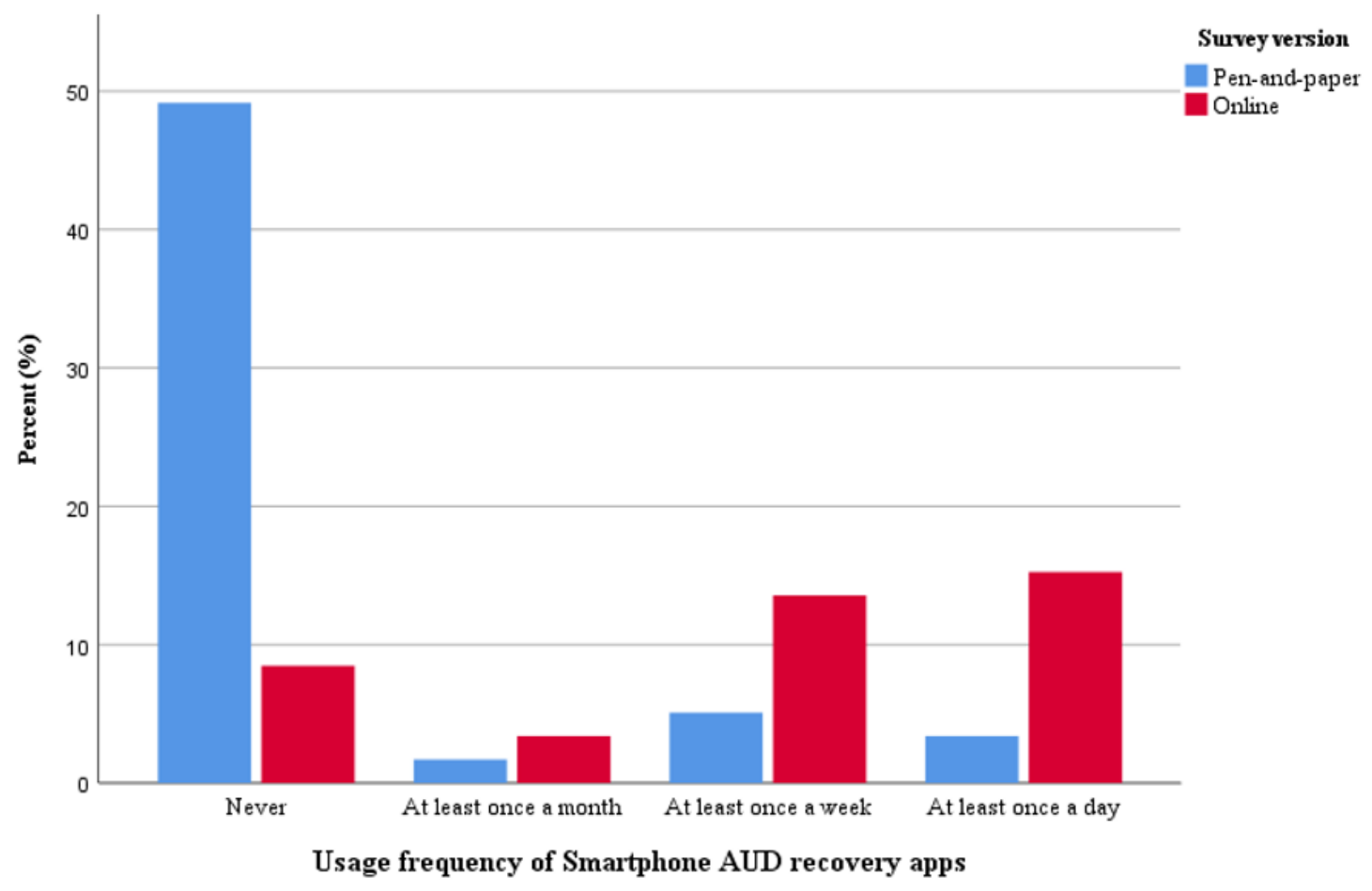

Figure 5. Usage Frequency of Smartphone AUD Recovery Apps by Survey Version

From Figure 5, it is apparent that most of the participants in the pen-and-paper sample never used Smartphone AUD recovery apps while the usage frequency of the online sample was more varied with many participants using these apps everyday to at least once a week, with the remaining few having never used these apps at all, or having used them at least once a month.

\section{Measurement Model}

After describing the sample, the theoretical underpinning of this study may now be analyzed. The measurement model will first be evaluated followed by the structural model.

The results of the reliability and validity testing of the constructs are displayed in Tables 11 and 12.

Table 11. 
Construct Reliability and Validity

\begin{tabular}{|c|c|c|c|c|c|}
\hline Constructs & Items & Loadings & Cronbach's Alpha & Average Variance Extracted (AVE) & Composite Reliability (CR) \\
\hline & EE1 & 0.816 & & & \\
\hline & EE2 & 0.841 & & & \\
\hline & EE3 & 0.688 & & & \\
\hline \multirow[t]{4}{*}{ Effort Expectancy } & EE4 & 0.656 & 0.841 & 0.569 & 0.893 \\
\hline & FC1 & -0.002 & & & \\
\hline & $\mathrm{FC} 2$ & 0.189 & & & \\
\hline & FC3 & 0.415 & & & \\
\hline \multirow[t]{3}{*}{ Facilitating Conditions } & FC4 & -0.072 & 0.501 & 0.053 & 0.069 \\
\hline & PE1 & 0.929 & & & \\
\hline & PE2 & 0.789 & & & \\
\hline \multirow[t]{4}{*}{ Performance Expectancy } & PE3 & 0.505 & 0.795 & 0.580 & 0.797 \\
\hline & SI1 & 0.559 & & & \\
\hline & SI2 & 0.713 & & & \\
\hline & SI3 & 0.850 & & & \\
\hline Social Influence & SI4 & 0.877 & 0.839 & 0.578 & 0.842 \\
\hline
\end{tabular}

The Cronbach's alpha is a measure of internal consistency reliability that assumes similar thresholds as Composite Reliability (CR) (Hair, Risher, Sarstedt, \& Ringle, 2019). Specifically, reliability values for Cronbach's alpha and CR should be between 0.60 and 0.70 which are considered "acceptable in exploratory research," and values between 0.70 and 0.90 are in the "satisfactory to good" range (Hair et al, 2019). From Table 10, the Cronbach's alpha and the CR values for all the constructs, except for facilitating conditions, are well above 0.70 , thus indicating high levels of reliability.

One measure of evaluating the convergent validity of reflective constructs is by examining the indicator reliability (size of the outer loadings) (Hair et al, 2017). To help establish convergent validity on a construct, an indicator's outer loading should be 0.708 or higher (Hair et al, 2017). From Table 11, EE1 and EE2 on effort expectancy, PE1 and PE2 on performance expectancy, and SI2, SI3, and SI4 on social influence have satisfactory loadings that are above the recommended 0.708 . This means that those constructs explain more than $50 \%$ of the indicator's variance, thus exhibiting acceptable item reliability (Hair, Risher, Sarstedt, \& Ringle, 2019). 
A second measure used to assess the convergent validity of constructs is the average variance extracted (AVE) which evaluates convergent validity on all items for each construct (Hair et al, 2019). Acceptable AVE values are of 0.50 and higher which indicates that the construct holds $50 \%$ explanatory power for the variance on each of its items (Hair et al, 2019). The AVE values for each of the constructs, except for facilitating conditions, are well above 0.50 , thereby indicating convergent validity.

Table 12.

Discriminant Validity (HTMT Ratios)

\begin{tabular}{|c|c|c|c|c|c|c|}
\hline \multirow{2}{*}{ Behavioral Intention } & Behavioral Intention & Effort Expectancy & Facilitating Conditions & Performance Expectancy & Social Influence & Use Behavior \\
\hline & & & & & & \\
\hline Effort Expectancy & .518 & & & & & \\
\hline Facilitating Conditions & .536 & .891 & & & & \\
\hline Performance Expectancy & .430 & 287 & .305 & & & \\
\hline Social Influence & .535 & 222 & .250 & 461 & & \\
\hline Use Behavior & .356 & .352 & 208 & .473 & 640 & \\
\hline
\end{tabular}

A preferred choice to assess the discriminant validity between constructs is the Heterotrait Monotrait (HTMT) ratio. When constructs are conceptually more distinct, as is the case with the constructs of UTAUT, a lower conservative threshold of .85 is suggested such that values above this threshold indicate a lack of discriminant validity (Hair et al, 2019). From Table 12,14 out of 15 comparisons are well under the threshold, thus indicating discriminant validity between the constructs - however, one comparison, facilitating conditions compared to effort expectancy, has a value of .891 which violates the .85 threshold. This indicates a lack of discriminant validity between these two constructs.

\section{Structural Model}

Since the measurement model assessment has mostly proven to be satisfactory, the structural model may be assessed. The PLS-SEM algorithm also obtains estimates for the 
structural model relationships — in other words, the path coefficients (Hair et al, 2017). The path coefficients, in turn, represent the hypothesized relationships among the constructs (Hair et al, 2017). With standardized values that are generally between -1 and +1 , estimated path coefficients that fall near either of these extremes represent strong negative, or strong positive, relationships (Hair et al, 2017). Figure 6 shows the path coefficients and the $\mathrm{R}^{2}$ values in the simple model which only includes the direct effects. On the other hand, Table 13 displays the path coefficients and the statistical significance of the relationships between the direct effects.

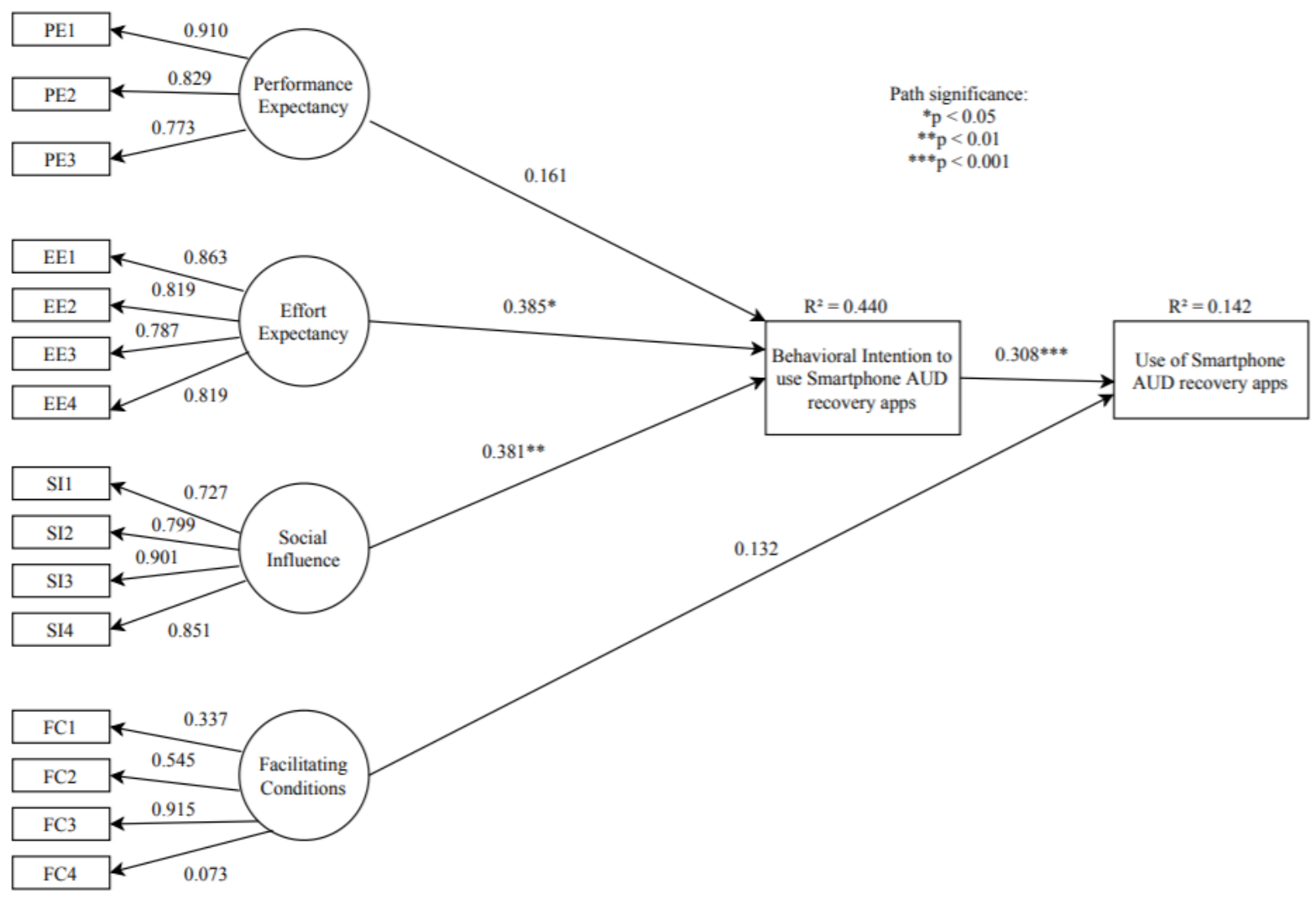

Figure 6. Simple Model: Path Coefficients and $\mathrm{R}^{2}$

Table 13.

Simple Model: Path Coefficients and Significance of Relationships 


\begin{tabular}{clrr}
\hline Hypothesis & \multicolumn{1}{c}{ Relationships } & Path Coeffcients & P Values \\
\hline H1 & Performance Expectancy $\rightarrow$ Behavioral Intention & 0.161 & .154 \\
H2 & Effort Expectancy $\rightarrow$ Behavioral Intention & $0.385^{*}$ & .046 \\
H3 & Social Influence $\rightarrow$ Behavioral Intention & $0.381^{* *}$ & .005 \\
H4 & Behavioral Intention $\rightarrow$ Use Behavior & $0.308^{* * *}$ & .000 \\
H5 & Facilitating Conditions $\rightarrow$ Use Behavior & 0.132 & .538
\end{tabular}

Note. Statistical significance: ${ }^{*} \mathrm{p}<0.05 ;{ }^{* *} \mathrm{p}<0.01 ; * * * p<0.001$

Illustrated in Figure 6 and reflected in Table 13, the relationships of performance expectancy, effort expectancy, and social influence on behavioral intention appear to be weak as the path coefficients are closer to 0 . The relationship between behavioral intention and use behavior also seems to be weak as it is closer to 0 . Lastly, the relationship between facilitating conditions and use behavior is also weak for the same reason. To investigate the statistical significance of the relationships, the p-values can be examined in Table 13. The significant relationships among the constructs with $\mathrm{p}$ values $<0.05$ were found to be effort expectancy on behavioral intention, social influence on behavioral intention, and behavioral intention on use behavior. The nonsignificant relationships with $\mathrm{p}$ values $>0.05$ were found to be performance expectancy on behavioral intention and facilitating conditions on use behavior.

The coefficient of determination, $\mathrm{R}^{2}$, is the most commonly used measure to evaluate the structural model (Hair et al, 2017). The $\mathrm{R}^{2}$ measures the variance in each of the endogenous constructs and quantifies the model's explanatory power (Hair et al, 2019). Higher $\mathrm{R}^{2}$ values generally indicate greater explanatory power (Hair et al, 2019). From Figure 6, the model explains $44.0 \%$ of the variance in behavioral intention and $14.2 \%$ of the variance in use behavior.

Next, PLS-SEM was used to analyze the complete model, which includes the indirect (moderating effects). Figure 7 shows the path coefficients and the $\mathrm{R}^{2}$ values on the complete 
model while Table 14 displays the path coefficients and the statistical significance of the relationships among the direct effects.

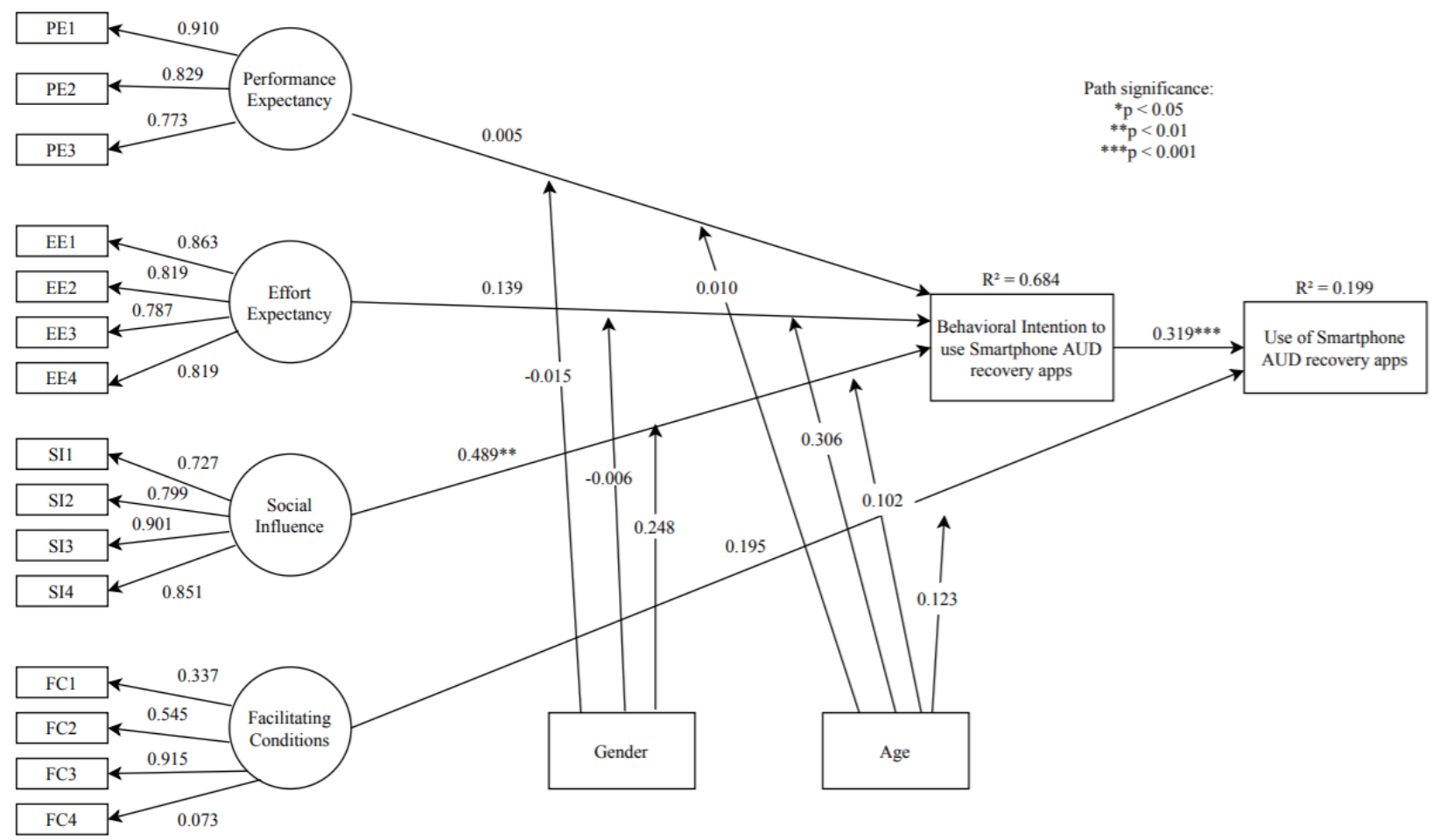

Figure 7. Complete Model: Path Coefficients and $\mathrm{R}^{2}$

Table 14.

Complete Model: Path Coefficients and Significance of Relationships 


\begin{tabular}{|c|c|c|c|c|c|}
\hline \multirow[b]{3}{*}{ Hypothesis } & \multirow[b]{3}{*}{ Predictor Variables } & \multicolumn{4}{|c|}{ Dependent Variables } \\
\hline & & \multicolumn{2}{|c|}{ Behavioral Intention } & \multicolumn{2}{|c|}{ Use Behavior } \\
\hline & & Path Coefficients & P Values & Path Coefficients & P Values \\
\hline H1 & $\mathbf{P E}$ & 0.005 & .972 & & \\
\hline $\mathbf{H} 2$ & EE & 0.139 & .447 & & \\
\hline H3 & SI & $0.489 * * *$ & .001 & & \\
\hline H4 & BI & & & $0.319 * *$ & .002 \\
\hline H5 & FC & 0.195 & .393 & & \\
\hline H1(a) & Gender X PE & -0.015 & .937 & & \\
\hline H2(a) & Gender X EE & -0.006 & .973 & & \\
\hline H3(a) & Gender X SI & 0.248 & .228 & & \\
\hline H1(b) & Age X PE & 0.010 & .956 & & \\
\hline H2(b) & Age $X$ EE & 0.306 & .052 & & \\
\hline H3(b) & Age X SI & 0.102 & .468 & & \\
\hline H4(a) & Age X FC & & & 0.123 & .408 \\
\hline
\end{tabular}

Note. Statistical significance: $* \mathrm{p}<0.05 ; * * \mathrm{p}<0.01 ; * * * \mathrm{p}<0.001$

As shown in Figure 7 and in Table 14, all direct and moderating relationships appear to be weakly correlated as their path coefficients are close to 0 , with the moderating effect of gender on effort expectancy and gender on performance expectancy showing weak negative relationships. From Figure 7, the complete model explains more variance with $68.4 \%$ of the variance being explained in behavioral intention and $19.9 \%$ of the variance being explained in use behavior, compared to $44.0 \%$ and $14.2 \%$, respectively, from the simple model. Hypotheses 3 and 4 were thus supported. Hypotheses 1, 1(a), 1(b), 2, 2(a), 2(b), 3(a), 3(b), 5, and 5(a) were not.

\section{Open-ended Responses}

The first survey asked three open-ended questions to investigate the reasons why participants would want to use Smartphone AUD recovery apps, why they would not want to use 
such apps, and for existing users of these apps, why they are using them. Table 15 lists these questions.

Table 15.

List of Open-ended Questions on the First Survey

\begin{tabular}{|c|l|}
\hline Question No. & \multicolumn{1}{c|}{ Open-ended Questions } \\
\hline $\mathbf{5}$ & "What would make you want to use one?" \\
\hline $\mathbf{6}$ & $\begin{array}{l}\text { "What would make you not want to use a Smartphone app to help you } \\
\text { recover from Alcohol Use Disorder (AUD)?" }\end{array}$ \\
\hline $\mathbf{8}$ & $\begin{array}{l}\text { "If you are using a Smartphone app that assists with recovery from } \\
\text { Alcohol Use Disorder (AUD), why are you using it?" }\end{array}$ \\
\hline
\end{tabular}

In response to question 5, some of the most frequently given reasons given by participants for wanting to use Smartphone AUD recovery apps included help in staying abstinent, accessibility, ease of use, ability to track drinking and days of not drinking, ability to track and calculate money saved by not drinking, ability to connect and engage with the community of fellow users, convenience, and ability to send mobile alerts. Respondents stated that Smartphone AUD recovery apps had to be "easily accessible", have "access to local resources", and be "accessible for android + apple" to make them want to use them. One respondent stated that they were something they would turn to if there was "no access to physical resources". Respondents stated that such apps had to be easy to use, convenient, and be "easy to track triggers and cravings in a timely manner".

The other major recurring themes in participants' responses to question 5 were "connection to resources" and "community". They stated that Smartphone AUD recovery apps should have the "community factor" that included "the ability to invite friends", have a "badges earned/gamified" element to it, and "provide you with instantaneous support or find a meeting 
close by". One respondent stated that some reasons why they would use such apps were if they could "monitor my urges/wants to drink. If I drank what to do- talk to people about it. If I felt an urge- talk to someone/or find information to help me not to drink.".

In response to question 6 , some of the most frequently given reasons by participants for why they would not want to use Smartphone AUD recovery apps were if there was a loss of data privacy and security, if their data and personal information were being stored, monitored, collected, sold, or disclosed to third parties, if the apps carried a cost to use, if they were expensive, and if the apps were complicated to use. Privacy and confidentiality were major features for participants that, if compromised, discouraged them from wanting to use Smartphone AUD recovery apps. Participants stated that "The potential of data tracking and possibility of using my information for profit" and "Privacy would be the only issue regarding using an app to help in recovery.". Another recurring theme in participants' responses to this question pertained to the complicatedness and lack of user-friendliness of the app. If the app was "confusing", “complicated", had a bad "interface and design", was not laid out "easily and nicely", or had a "clunky interface/bugginess", participants would not want to use them.

Lastly, in response to question 8, the few existing users of Smartphone AUD recovery apps cited the convenience, ease of use, features of tracking drinking, abstinence, and cost savings, along with recommendations given by friends or medical professionals, as being major reasons why they used these apps. With regards to other specific features that users enjoyed, one respondent stated that it gave them "a reading everyday to consider", while another stated that it gave them "Daily quotes". 
Given the findings outlined in this section, the results are discussed in the next section followed by the implications of the findings and the next steps for future research. The limitations are also discussed, and finally, conclusions are obtained from this study.

\section{DISCUSSION}

This study investigated the determinants of behavioral intention to use Smartphone AUD recovery apps within an adult population of those who self-identified as having an AUD. The study also explored participants' reasons for wanting to use or not use such apps. The results from the theoretical assessment of this study showed that social influence is the sole significant correlate of behavioral intention to use Smartphone AUD recovery apps. This means that participants were highly receptive to the opinions of important others in their lives, including the opinions of their caregivers, in deciding whether they want to use Smartphone AUD recovery apps. In fact, participants' behavioral intention to use these apps had less to do with the benefits they expected to receive from them or how easy they perceived them to be to use, and more to do with what important others had to say about them. What, then, do potential AUD recovery app users expect from these apps? Are their behavioral intentions to use these apps shaped by factors related to social acceptance? This calls attention to the need for further research to answer these questions. This study also found that behavioral intention to use these apps is significantly correlated with use behavior. In other words, increased behavioral intention to use Smartphone AUD recovery apps was accompanied with increased use behavior. Participants who indicated their intention to want to use, or continue to use, Smartphone AUD recovery apps, reflected this intention in their usage behavior. 
These findings helped contribute to knowledge on the antecedents and the use of Smartphone AUD recovery apps. It highlighted the importance of social influencing factors in shaping an individual's decision to accept these apps in addition to confirming the presence of a relationship between an individual's acceptance of these apps and their adoption of them. There were, however, also hypotheses that were unsupported in this study. These unsupported relationships included performance expectancy and effort expectancy on behavioral intention and facilitating conditions on use behavior. This leads to the consideration that UTAUT may not be the most appropriate IT acceptance model to use when investigating the determinants of behavioral intention to use a technology within a population of those with AUD. A search of the literature also yielded results that were similar to the ones found in this study. These unsupported relationships, however, may also be due to the small sample size.

There was no association found between the benefits participants would expect to receive from using Smartphone AUD recovery apps and their intention to want to use them. Although participants indicated that they would find these apps to be beneficial to their recovery, this did not make them more inclined to want to use them. The lack of significance between performance expectancy and behavioral intention also contradicts other research studies that used UTAUT. In fact, studies and empirical reviews of UTAUT have singularly pointed to the construct of performance expectancy as being the main driver of technology acceptance (Taiwo \& Downe, 2013; Williams et al, 2015; Dwivedi et al, 2017; Apolinário-Hagen et al, 2019). The more one perceives an mHealth app to benefit their health, the stronger their intention is to use it (Carlsson, 2006; Hoque and Sorwar, 2017, Nunes, Limpo, \& Castro, 2019; Sun et al., 2013). Although this relationship was found to be insignificant in this study, it does not stand alone in this finding. Other studies which used UTAUT in the context of ICT acceptance and adoption, have also 
found this relationship to be insignificant (Birch \& Irvine, 2009; Tibenderana et al, 2010; Attuquayefio \& Addo, 2014). None of these studies, however, investigated possible explanations for this insignificant finding.

The relationship of effort expectancy on behavioral intention was also found to be unsupported in this study. Despite participants scoring generally high on the effort expectancy items which indicated that they would find Smartphone AUD recovery apps easy to use, this was not correlated with their intention to want to use them. This finding is not in line with Venkatesh et al's (2003) research nor is it in line with Sun et al's (2013) review of theoretical models applied to mHealth, which found that both constructs of social influence and effort expectancy should be considered when investigating consumer health technology acceptance. Nevertheless, an insignificant relationship between effort expectancy and behavioral intention is not a new finding — it has been reflected in other studies that used UTAUT in the context of mHealth (Alam, Hoque, Hu, \& Barua, 2020; Nunes et al, 2019).

Participants' responses to the open-ended questions on the survey are key to potentially explaining the insignificant relationships between performance expectancy on behavioral intention and effort expectancy on behavioral intention. A major reason given by participants as to why they would not want to use Smartphone AUD recovery apps, was if their privacy, or if their confidentiality, or both, were being compromised in any way. Moreover, several participants were skeptical that their anonymity in this study would be protected. These participants openly vocalized their fear that their participation in the study would entail the forfeiture of their anonymity, despite being told that their anonymity would be protected. This fear was assuaged in some participants while it was not in others, which ultimately resulted in 
their refusal to participate. Thus, data privacy concerns could have played into participants' behavioral intention to use them.

This fear has been echoed in many other studies in which respondents cited data privacy concerns for not using mHealth apps (Atienza et al, 2015; Kao \& Leibovitz, 2017; Kotz et al, 2016; Krebs \& Duncan, 2015; Zhou et al, 2019). Thus, although participants in this study indicated that these apps could have aided their recovery efforts (performance expectancy) and that they would have been easy to use (effort expectancy), these reasons may have not sufficed. If participants carried fears of privacy or confidentiality breaches as a result of using these apps, this could have trumped the perceived benefits and dampened their intention to want to use them.

The construct of facilitating conditions and its hypothesized positive relationship with use behavior is another relationship that was found to be uncorrelated and insignificant in this study. Although participants indicated that they have the resources and the knowledge necessary to use Smartphone AUD recovery apps, this did not relate in any significant way to their intention to want to use them. Other studies have also found this counterintuitive result (AlGahtani, Hubona, \& Wang, 2007; Hoque \& Sorwar, 2017).

Hoque and Sorwar (2017), in their study investigating mHealth adoption by the elderly, pointed to their study's cultural and socio-economic context, as being a major contributor to this insignificant finding. They explained that in a developing country like Bangladesh, in which their study took place, the elderly, who are dependent on their family members for care, are more influenced by social pressures than "by facilitating factors, such as the availability of human assistance" to shape their technology adoption decisions (Hoque \& Sorwar, 2017). Despite the differences in cultural and socio-economic contexts, this explanation may be extended to this research as well. 
Unlike Hoque and Sorwar's (2017) study, this study took place in a developed country and participants ranged in all ages over 18 years old. Moreover, at least for the respondents in the addiction treatment facilities, staff were their primary caregivers - not family. Yet, like in Hoque and Sorwar's (2017) study, participants in this study were highly receptive to social influence. In their answers to the open-ended questions, participants routinely cited recommendations by friends or medical caregivers as being a large contributor to their decision to use Smartphone AUD recovery apps. Moreover, a strong correlation between social influence and behavioral intention to use these apps was indeed confirmed in this study. Thus, Hoque and Sorwar's (2017) explanation may also hold true here-participants seem to be far more influenced by social pressures than the availability of human assistance, or other resources, to shape their adoption decisions of Smartphone AUD recovery apps.

It is also important to note that the moderating variables of gender and of age were found to have insignificant moderating effects on the constructs. Gender was hypothesized to influence the constructs of performance expectancy, effort expectancy, and social influence, except for the construct of facilitating conditions. Age, on the other hand, was hypothesized to influence all four constructs. This lack of significance is surprising since it goes against commonly held assumptions of both variables playing a role in technology acceptance. As such, these findings are inconsistent with many studies in the IT acceptance literature that point to the significance of these moderating variables (Alam et al, 2020; Bandyopadhyay \& Fraccastoro, 2007; Borrero et al, 2014; Rho et al, 2015; Venkatesh et al., 2003). They are, however, consistent with some studies.

The lack of significance in age as a moderating variable was found in a study that used UTAUT (Al-Gahtani et al, 2007), however, the authors did not explain possible reasons behind 
this insignificance. In another study, set in the context of mHealth, an extended TAM model was used wherein the variables of gender and of age were hypothesized to predict behavioral intention to use mHealth technology (Duo, Yu, Deng, Liu, Guan, Li, Ji, Du, Lu, \& Duan, 2017). The authors found both variables to have an insignificant influence on behavioral intention (Dou et al, 2017). The potential reasons for why both gender and age were found to be insignificant in their hypothesized relationships were also unexplained in this study.

A possible reason to explain the insignificance of gender and of age as moderating variables in this study may be due to the ubiquity of Smartphones - almost everyone seems to be using them. The previously mentioned Ashford et al (2018) study also found this prevalence in 259 surveyed respondents from 4 different addiction treatment facilities. They found that $93.8 \%$ of their respondents owned mobiles phones and $64.1 \%$ owned phones with app capabilities. Similarly, in this study, out of the 160 respondents who participated, only two individuals did not own a Smartphone - both from addiction treatment facilities. Since it was a prerequisite to own a Smartphone to participate in the study, their data were not considered for analysis. Nevertheless, this $98.8 \%$ Smartphone ownership rate among the respondents points to the widespread use of Smartphones. A recent study by the Pew Research Centre showed that, in advanced economies, the age gap in Smartphone ownership has been closing since 2015 (Silver, 2019). Furthermore, in both advanced and emerging economies, men and women were found to use technology at similar rates (Silver, 2019).

Naturally, those who use Smartphones are bound to use an app(s). Thus, on account of Smartphone ownership, and arguably, app usership, being commonplace in today's Canadian society, the moderating variables of gender and of age may be diminishing in importance. Still, further research is required to establish this claim. While the reasons that were explored above 
are partially speculative in nature, we were able to hear from the participants themselves on the factors leading to their acceptance, or rejection, of these apps, in the open-ended questions component of the survey.

The open-ended questions yielded other useful insights into what would make those with AUD want to use Smartphone AUD recovery apps, what would turn respondents away from wanting to use these apps, and why existing users are using them. Generally, tracking alcohol use and days spent sober, along with calculations of money saved by not drinking, and engagement with both the local community and connection to resources, were app features that encouraged respondents to want to use the apps. The most frequently given reasons for why respondents would not want to use these apps were if the apps breached confidentiality or used their personal information for profit. Lastly, app-specific features such as tracking of drinking and of abstinence, calculations of cost savings, receiving daily quotes or readings, and external factors such as having the apps recommended to the respondents by friends or medical staff, all contributed to why existing users continued to use the apps.

Furthermore, as previously mentioned, the advice by the management at the addiction treatment facilities were taken on the phrasing and the use of appropriate terminology. For one, it was recommended to use lay-person language in the recruitment speech, consent form, and survey. This was important not only to improve accessibility and foster inclusiveness, but also to motivate the clients to engage with the research. At many of the facilities which use the Alcoholics Anonymous (AA) 12 Steps/12 Traditions model of recovery, clients are taught that their illness is not something that they can "manage" or be "cured from". Thus, the word "manage" and any phrase insinuating complete recovery were omitted from the recruitment speech and all client-facing materials. Along these lines, it was also advised to rephrase one of 
the UTAUT performance expectancy questionnaire items that used "recovery more quickly" and replace it with something along the lines of "help me learn recovery skills more quickly".

The direction from management at these facilities highlights the discrepancies between traditional in-person treatment modalities and Smartphone AUD recovery apps. These discrepancies lie in the former being rooted in a particular philosophy and employing evidencebased approaches for addiction treatment while the latter may not necessarily be founded on these approaches. This can pose as an area of concern for medical staff in recommending these apps to clients on account of these reasons.

The importance of app features of community support and engagement, which the respondents in this study cited as a major contributing reason for wanting to use Smartphone AUD recovery apps, confirms prior findings. The Ashford et. al (2018) study that was mentioned earlier in this paper, found that the majority of the patients in the addiction treatment facilities they surveyed, expressed interest in joining an online support group (69.0\%) or Facebook support group (62.3\%) to support their personal recovery. These findings reinforce the importance of receiving community support and engagement to aid recovery efforts in an addiction population.

The open-ended responses given by the participants for why they would want to use or not use Smartphone AUD recovery apps also confirmed the findings from Savic et al's (2013) and Crane et al's (2017) studies. Specifically, participants in this study also expressed the ease of use of apps, its aesthetic appeal, and tracking abilities, among other things, as being incentives to use these apps. Like the respondents in Savic et al's (2013), respondents in this study were also put off by Smartphone AUD recovery apps if they carried a cost to use, had technical glitches, and if they were not user-friendly 


\section{IMPLICATIONS OF FINDINGS AND FUTURE RESEARCH}

The findings from this study demonstrated the importance of social influence for potential users of Smartphone AUD recovery apps and highlighted the most important app features that incentivized or discouraged participants from wanting to use the apps. The study also brought attention to various areas that call for improvement and for further research. For one, future research may include a larger sample size to address the small sample problem encountered in this study. Recruitment efforts may also be directed to primarily addiction treatment facilities, as opposed to online, to circumvent the survey response quality issues that were found in the online sample of this study. Lastly, this study indicates that further research is required to create empirically validated UTAUT scales to apply to an AUD population.

The UTAUT scales which were used in this study were modified to fit the context of the target population (those with AUD) and the technology in question (Smartphone AUD recovery apps). Since these modifications were unique to this study, further research needs to be conducted to test the reliability and the validity of the scale measures that were used. The construct of facilitating conditions, in particular, did not adequately pass the reliability and the

validity testing. Thus, future research using UTAUT in a population of AUD sufferers, may look into creating new measures for this construct that are more reliable and more valid.

The confirmed hypotheses of the study, namely, the highly statistically significant relationship between social influence and behavioral intention to use Smartphone AUD recovery apps, and the moderately statistically significant relationship between behavioral intention on use behavior, carry important implications for the development and the marketing of these apps. These findings show that not only are participants sensitive to others' influence in shaping their 
own decisions to use these apps, but once they intend to use or keep using these apps, this largely translates to use, or continued use, behavior.

Along these lines, participants cited recommendations from friends or HCPs as being the major drivers of use behavior. Evidently, social influence is the first link of this chain of relationships. As such, app developers may engage in partnerships with addiction treatment facilities and with HCPs to help spread the word of these apps. To further attract app usage, app developers may incorporate or enhance features that provide social networking, access to local resources, and community engagement, and market their apps accordingly. Healthcare providers may also be encouraged to incorporate the use of Smartphone AUD recovery apps in patients' treatment plans. The moderators of social media AUD recovery support groups can also use this knowledge to raise awareness of the existence of these apps to their followers. Lastly, a hoped benefit of this study was to raise awareness of the existence of these apps which AUD sufferers may use to assist their recovery.

\section{LIMITATIONS}

This study has limitations. Although 160 individuals participated, this study struggled with a small sample size. This was because after the survey data was analyzed to ensure that the respondents met the eligibility criteria and that their responses passed the survey quality checks, the responses of only 59 individuals remained.

Given that an even smaller number of individuals participated in the follow-up survey, this resulted in the abandonment of the study's longitudinal aim. Future research may focus on recruiting a larger sample size and to make the study longitudinal in design to capture usage behavior over time and the long-term effects of these apps on the respondents. 
Also, since it was mainly the online respondents with which there were the most response quality issues, this brings into light the problems associated with online surveys, and survey research, in general. Participants may not have been encouraged to answer the survey truthfully or accurately, or they may have had a problem with the incentive which could have affected their willingness to take the survey in earnest. Although there were some differences between the online and the pen-and-paper subsamples in this study, particularly relating to the level of selfidentification with AUD, and past knowledge and use of AUD recovery apps, the differences between them were not drastic. For example, both subsamples displayed similar rates of technology acceptance, among other things. Rather, the only drastic difference between them was the greater extent to which the online responses had to be shed, compared to the in-person subsample, due to the quality issues described earlier.

In addition to the limitations brought on by the study's small sample size, there are limitations that stem from the uniqueness of the population that was studied-namely, those with AUD. For one, those recruited from the addiction treatment facilities more strongly identified with the definition of AUD than those recruited from online. It is a possibility that the online respondents were underreporting the extent to which they identified themselves as having an AUD. Several studies (Sobell \& Sobell, 2004; Stockwell, Zhao, \& Macdonald, 2014; Zhao, Stockwell, \& Thomas, 2015) which examined many self-report surveys of alcohol use found an underreporting problem of alcohol consumption in the general population. Thus, this selfreporting issue poses a limitation for the accuracy of the online respondents' self-identification with AUD.

Furthermore, a study by Bates, Bowden, and Barry (2002) found that almost 50-80\% of those with an AUD have neurocognitive impairments. These cognitive impairments include 
"poor planning ability, memory impairment, inflexibility of thought processes, inability to appropriately respond to environmental cues, and difficulty in developing goals or orienting behavior toward future goals" (Bates et al, 2002, p. 193). In another study by Mulhauser, Weinstock, Ruppert, and Benware (2018), individuals with an AUD remained cognitively impaired through the initial phase of treatment. Thus, respondents may have had a hard time accurately answering the survey questions as some of the questions asked for a recollection of past use of AUD recovery apps and the frequency of usage. Moreover, the non-users of these apps may have experienced increased difficulties in answering many of the UTAUT items since they were future oriented. For example, one item measuring performance expectancy asked respondents whether "Using Smartphone Alcohol Use Disorder (AUD) recovery apps helps/would help me learn recovery skills more quickly". If they were experiencing cognitive impairments as a result of their AUD, they may not have been able to answer these questions accurately. Thus, the small sample size of this study coupled with the uniqueness of the population that was studied may potentially explain the study's results and may also potentially call into question the validity of the data.

There are also methodological limitations concerning the survey instrument itself. Considering that the UTAUT questionnaire items were modified to fit the context of this study, the reliability and validity of the modified UTAUT items are called into question. This was slightly reflected in the reliability and validity testing of the UTAUT items in this study for which facilitating conditions was found to be a problematic construct. The original UTAUT2 operationalizations for behavioral intention were also reduced so that only one item was retained, modified, and used. Only one item was retained because the other two items in UTAUT2 assumed past and present use of the technology — assumptions which could not be made in this study for reasons 
outlined earlier in the paper. Nevertheless, this poses as a limitation because single-item constructs reduce the quality of the measurement (Hair et. al, 2017). Thus, the modified UTAUT scales that were used in this study, are susceptible to flaws since the modifications are not empirically validated.

\section{CONCLUSION}

Substance use in Canada results in high economic costs - alcohol being responsible for most of these costs. Those with alcohol addiction can benefit greatly from receiving treatment which is traditionally offered through in-person modalities. Recently, mHealth has emerged as an accompaniment to traditional treatment. The field of mHealth as it pertains to alcohol addiction, has shown promising results in the efficacy of these technologies for improving AUD treatment outcomes. This study identified the importance of social influences to explain behavioral intention to use these apps using the framework of an empirically validated and widely used, IT acceptance theory of UTAUT.

This study offers a unique contribution to the literature by illustrating that social influence is the only single correlate of behavioral intention to use Smartphone AUD recovery apps and that behavioral intention is correlated to use behavior. Additional insights gleaned from the open-ended questions, highlighted features that are important to potential users-particularly concerning data privacy. Lastly, this study raised awareness of the existence of such apps to AUD sufferers who may use them to assist with their recovery.

While this study, drawing on the literature, highlighted the benefits that AUD sufferers can potentially gain by using Smartphone AUD recovery apps, there are some caveats. The fight against addiction cannot be won by the use of Smartphone AUD recovery apps alone. As this 
study has shown, social influencing factors are what matter most, and they may be integral to AUD recovery. Thus, it remains a concerted social effort — one which requires the continuous cross-collaboration of scientists, HCPs, technology companies, and the potential end users themselves - those with AUD, to help inform and shape the future of AUD treatment. 


\section{APPENDIX}

\section{Survey Instrument: First Survey}

Please read the questions below. Most will ask you to circle the answer that you think fits best, while some questions will ask you to explain your answer briefly.

1. Is your level of alcohol consumption concerning to you? Here is the technical term and definition of Alcohol Use Disorder (AUD), defined as "a chronic and relapsing brain disease characterized by compulsive alcohol use, loss of control over alcohol intake, and a negative emotional state when not using"? How much does this definition sound like you? Please circle one.

Not at all like me Somewhat like me Very much like me Prefer not to answer

2. Do you own a Smartphone? Please circle one.

$$
\text { Yes No Prefer not to answer }
$$

3. Before taking this survey, were you aware of the existence of Smartphone apps that can be used to help with (not substitute) recovery from Alcohol Use Disorder (AUD)? Please circle one.

$$
\text { Yes } \quad \text { No Prefer not to answer }
$$

4. Have you ever used a Smartphone app for recovering from Alcohol Use Disorder (AUD)? Please circle one.

$$
\text { Yes No Prefer not to answer }
$$


Please turn page for the next question.

5. What would make you want to use one? Please outline your reasons in the text box below.

6. What would make you not want to use a Smartphone app to help you recover from Alcohol Use Disorder (AUD)? Please outline your reasons in the text box below.

7. Are you currently using a Smartphone app to help you recover from Alcohol Use Disorder (AUD)? Please circle one.

Yes No Prefer not to answer 
8. If you are using a Smartphone app that assists with recovery Alcohol Use Disorder (AUD), why are you using it? Please outline your reasons in the text box below.

9. If you are using a Smartphone app that assists with recovery Alcohol Use Disorder (AUD), how often do you use it? Please choose one of the following:

Every day At least once a week At least once a month

At least once every 3 months At least once every 6 months At least once a year

Prefer not to answer

10. I find/would find Smartphone Alcohol Use Disorder (AUD) recovery apps useful in complementing the daily activities I do to help me recover. Please circle one.

Strongly Disagree Disagree Undecided Agree Strongly Agree

Prefer not to answer 
11. Using Smartphone Alcohol Use Disorder (AUD) recovery apps helps/would help me learn recovery skills more quickly. Please circle one.

$$
\text { Strongly Disagree Disagree Undecided Agree Strongly Agree }
$$

Prefer not to answer

12. Using Smartphone Alcohol Use Disorder (AUD) recovery apps helps/would help me increase the effectiveness of activities I do to help me recover. Please circle one.

Strongly Disagree Disagree Undecided Agree Strongly Agree

Prefer not to answer

13. Learning how to use Smartphone Alcohol Use Disorder (AUD) recovery apps is/would be easy for me. Please circle one.

Strongly Disagree Disagree Undecided Agree Strongly Agree

Prefer not to answer

14. My interaction with Smartphone Alcohol Use Disorder (AUD) recovery apps is/would be clear and understandable. Please circle one.

Strongly Disagree Disagree Undecided Agree Strongly Agree

Prefer not to answer 
15. I find/would find Smartphone Alcohol Use Disorder (AUD) recovery apps addiction recovery apps easy to use. Please circle one.

$$
\text { Strongly Disagree Disagree Undecided Agree Strongly Agree }
$$

Prefer not to answer

16. It is/would be easy for me to become skillful at using Smartphone Alcohol Use Disorder (AUD) recovery apps. Please circle one.
Strongly Disagree
Disagree
Undecided
Agree Strongly Agree

Prefer not to answer

17. People who are important to me think that I should use Smartphone Alcohol Use Disorder (AUD) recovery apps. Please circle one.

Strongly Disagree Disagree Undecided Agree Strongly Agree

Prefer not to answer

18. Caregivers think that I should use Smartphone Alcohol Use Disorder (AUD) recovery apps. Please circle one.

Strongly Disagree Disagree Undecided Agree Strongly Agree

Prefer not to answer 
19. People who influence my behavior think that I should use Smartphone Alcohol Use Disorder (AUD) recovery apps. Please circle one.

$$
\text { Strongly Disagree Disagree Undecided Agree Strongly Agree }
$$

Prefer not to answer

20. People whose opinions that I value prefer that I use Smartphone Alcohol Use Disorder (AUD) recovery apps. Please circle one.

Strongly Disagree Disagree Undecided Agree Strongly Agree

Prefer not to answer

21. I have the resources necessary to use Smartphone Alcohol Use Disorder (AUD) recovery apps. Please circle one.

Strongly Disagree Disagree Undecided Agree Strongly Agree

Prefer not to answer

22. I have the knowledge necessary to use Smartphone Alcohol Use Disorder (AUD) recovery apps. Please circle one.

Strongly Disagree Disagree Undecided Agree Strongly Agree

Prefer not to answer 
23. Smartphone Alcohol Use Disorder (AUD) recovery apps are compatible with other technologies I use. Please circle one.

Strongly Disagree Disagree Undecided Agree Strongly Agree

Prefer not to answer

24. I can get help from others to use Smartphone Alcohol Use Disorder (AUD) recovery apps. Please circle one.

Strongly Disagree Disagree Undecided Agree Strongly Agree

Prefer not to answer

25. Do you intend to use or keep using a Smartphone Alcohol Use Disorder (AUD) recovery app(s)? Please choose one of the following:

Yes No Not sure Prefer not to answer

26. What is your gender? Please choose one of the following:

Male Female Other Prefer not to answer

27. What is your age? Please write your age in years in the space below. 
28. May we contact you to complete a follow-up online survey in a month's time? You will receive the same incentive (\$5 gift voucher towards Amazon) for participating in this follow-up survey.

$$
\text { Yes No Prefer not to answer }
$$

If you answered "yes" to the question above, please provide your e-mail address (required) and phone number (optional) in the space below:

E-mail address:

Phone \#:

You have reached the end of the survey. Thank you for participating! 


\section{REFERENCES}

Alam, M. Z., Hoque, M. R., Hu, W., \& Barua, Z. (2020). Factors influencing the adoption of mHealth services in a developing country: A patient-centric study. International Journal of Information Management, 50, 128-143. doi:10.1016/j.ijinfomgt.2019.04.016

Al-Gahtani, S. S., Hubona, G. S., \& Wang, J. (2007). Information technology (IT) in saudi arabia: Culture and the acceptance and use of IT. Information \& Management, 44(8), 681-691. doi:10.1016/j.im.2007.09.002

American Addiction Centers. (2019, September 25). Binge Drinking: When Does it Become a Problem? Retrieved from https://americanaddictioncenters.org/alcoholismtreatment/binge-drinking-problem

American Society of Addiction Medicine. (2011). Retrieved from https://www.asam.org/resources/definition-of-addiction

Apolinário-Hagen, J., Hennemann, S., Fritsche, L., Drüge, M., \& Breil, B. (2019). Determinant factors of public acceptance of stress management apps: Survey study. JMIR Mental Health, 6(11), e15373. doi:10.2196/15373

Ashford, R. D., Lynch, K., \& Curtis, B. (2018). Technology and social media use among patients enrolled in outpatient addiction treatment programs: Cross-sectional survey study. Journal of Medical Internet Research, 20(3), e84. doi:10.2196/jmir.9172

Atienza, A. A., Zarcadoolas, C., Vaughon, W., Hughes, P., Patel, V., Chou, W. S., \& Pritts, J. (2015). Consumer attitudes and perceptions on mHealth privacy and security: Findings 
from a mixed-methods study. Journal of Health Communication, 20(6), 673-679. doi:10.1080/10810730.2015.1018560

Attuquayefio, S. N., \& Addo, H. (2014). Using the UTAUT model to analyze students' ICT adoption. International Journal of Education \& Development using Information \& Communication Technology, 10(3), 75-86.Attwood, S., Parke, H., Larsen, J., \& Morton, K. L. (2017). Using a mobile health application to reduce alcohol consumption: A mixedmethods evaluation of the drinkaware track \& calculate units application. England: BioMed Central. doi:10.1186/s12889-017-4358-9

Bates, M. E., Bowden, S. C., \& Barry, D. (2002). Neurocognitive impairment associated with alcohol use disorders: Implications for treatment. Experimental and Clinical Psychopharmacology, 10(3), 193-212. doi:10.1037/1064-1297.10.3.193

Becker, D. (2016). Acceptance of mobile mental health treatment applications Elsevier B.V. doi:10.1016/j.procs.2016.09.036

Becker, S., Miron-Shatz, T., Schumacher, N., Krocza, J., Diamantidis, C., \& Albrecht, U. (2014). mHealth 2.0: Experiences, possibilities, and perspectives. JMIR mHealth and uHealth, 2(2), e24. doi:10.2196/mhealth.3328

Birch, A., \& Irvine, V. (2009). Preservice teachers' acceptance of ICT integration in the classroom: Applying the UTAUT model. Educational Media International, 46(4), 295315. doi:10.1080/09523980903387506

Borrero, J. D., Yousafzai, S. Y., Javed, U., \& Page, K. L. (2014). Expressive participation in internet social movements: Testing the moderating effect of technology readiness and sex 
on student SNS use. Computers in Human Behavior, 30, 39-49.

doi:10.1016/j.chb.2013.07.032

Canadian Centre on Substance Use and Addiction, \& Canadian Executive Council of Addictions. (2017, November). Finding Quality Addiction Care in Canada: Drug and Alcohol Treatment Guide. Retrieved from https://www.ccsa.ca/sites/default/files/2019-04/CCSAAddiction-Care-in-Canada-Treatment-Guide-2017-en.pdf

Canadian Centre on Substance Use and Addiction. (2018). Issue. Retrieved from http://www.ccdus.ca/Eng/Opioids/issue/Pages/default.aspx

Canadian Centre on Substance Use and Addiction, \& Canadian Institute for Substance Use Research (2018, October). Canadian Substance Use Costs and Harms: 2007-2014. Retrieved from http://www.ccdus.ca/Resource Library/CSUCH-Canadian-SubstanceUse-Costs-Harms-Report-2018-en.pdf

Canadian Centre on Substance Use and Addiction. (2018). Canada's Low-Risk Alcohol Drinking Guidelines [brochure]. Retrieved from https://www.ccsa.ca/canadas-low-risk-alcoholdrinking-guidelines-brochure

Carlsson, B. (2006). Internationalization of innovation systems: A survey of the literature. Res. Policy 35, 56-67. doi: 10.1016/j.respol.2005.08.003

Centre for Addiction and Mental Health (CAMH). (2018). Mental Illness and Addiction: Facts and Statistics. Retrieved from https://www.camh.ca/en/driving-change/the-crisis-is$\underline{\text { real/mental-health-statistics }}$ 
Chih, Ming-Yuan, M.H.A., M.S., Patton, T., B.S., McTavish, F. M., M.S., Isham, A. J., M.S., Judkins-Fisher, C. L., B.S., Atwood, A. K., Ph.D., \& Gustafson, D. H., Ph.D. (2013;2014;). Predictive modeling of addiction lapses in a mobile health application. Journal of Substance Abuse Treatment, 46(1), 29-35.

doi:10.1016/j.jsat.2013.08.004

Crane, D., Garnett, C., Brown, J., West, R., \& Michie, S. (2017). Factors influencing usability of a smartphone app to reduce excessive alcohol consumption: Think aloud and interview studies. Frontiers in Public Health, 5, 39. doi:10.3389/fpubh.2017.00039

Dou, K., Yu, P., Deng, N., Liu, F., Guan, Y., Li, Z., . . Duan, H. (2017). Patients' acceptance of smartphone health technology for chronic disease management: A theoretical model and empirical test. JMIR mHealth and uHealth, 5(12), e177. doi:10.2196/mhealth.7886

Dwivedi, Y. K., Dwivedi, Y. K., Rana, N. P., Rana, N. P., Jeyaraj, A., Jeyaraj, A., .. Williams, M. D. (2019). Re-examining the unified theory of acceptance and use of technology (UTAUT): Towards a revised theoretical model. Information Systems Frontiers, 21(3), 719-734. doi:10.1007/s10796-017-9774-y

Fowler, L. A., Holt, S. L., \& Joshi, D. (2016). Mobile technology-based interventions for adult users of alcohol: A systematic review of the literature. Addictive Behaviors, 62, 25-34. doi:10.1016/j.addbeh.2016.06.008

Guo, X., Zhang, X., \& Sun, Y. (2016). The privacy-personalization paradox in mHealth services acceptance of different age groups. Electronic Commerce Research and Applications, 16, 55-65. doi:10.1016/j.elerap.2015.11.001 
Gustafson DH, McTavish FM, Chih M, et al. A Smartphone Application to Support Recovery From Alcoholism: A Randomized Clinical Trial. JAMA Psychiatry. 2014;71(5):566-572. doi:10.1001/jamapsychiatry.2013.4642

Hair, J. F., Hult, G. T. M., Ringle, C. M., \& Sarstedt, M. (2017). A primer on partial least squares structural equation modeling (PLS-SEM) (Second ed.) SAGE.

Hair, J. F., Risher, J. J., Sarstedt, M., \& Ringle, C. M. (2019). When to use and how to report the results of PLS-SEM. European Business Review, 31(1), 2-24. doi:10.1108/EBR-11-20180203

Health Canada (2018, October 30). Canadian Tobacco, Alcohol and Drugs Survey (CTADS): Summary of results for 2017. Retrieved from https://www.canada.ca/en/healthcanada/services/canadian-tobacco-alcohol-drugs-survey/2017-summary.html

Hoeppner, B. B., Schick, M. R., Kelly, L. M., Hoeppner, S. S., Bergman, B., \& Kelly, J. F. (2017). There is an app for that - or is there? A content analysis of publicly available smartphone apps for managing alcohol use. Journal of Substance Abuse Treatment, 82, 67-73. doi:10.1016/j.jsat.2017.09.006

Hoque, R., \& Sorwar, G. (2017). Understanding factors influencing the adoption of mHealth by the elderly: An extension of the UTAUT model. International Journal of Medical Informatics, 101, 75-84. doi:10.1016/j.ijmedinf.2017.02.002

IBM Corp. Released 2017. IBM SPSS Statistics for Windows, Version 26.0. Armonk, NY: IBM Corp. 
Kaium, M. A., Bao, Y., Alam, M. Z., Hasan, N., \& Hoque, M. R. (2019). Understanding the insight of factors affecting mHealth adoption: A systematic review. International Journal of Research in Business and Social Science, 8(6), 181-200. doi:10.20525/ijrbs.v8i6.522

Kao, C., MD, \& Liebovitz, D. M., MD. (2017). Consumer mobile health apps: Current state, barriers, and future directions. $P m \& r, 9(5)$, S106-S115. doi:10.1016/j.pmrj.2017.02.018

Kazemi, D. M., Borsari, B., Levine, M. J., Li, S., Lamberson, K. A., \& Matta, L. A. (2017). A systematic review of the mHealth interventions to prevent alcohol and substance abuse. Journal of Health Communication, 22(5), 413-432. doi:10.1080/10810730.2017.1303556

Kotz, D., Gunter, C. A., Kumar, S., \& Weiner, J. P. (2016). Privacy and security in mobile health: A research agenda. Computer, 49(6), 22-30. doi:10.1109/MC.2016.185

Krebs, P., \& Duncan, D. T. (2015). Health app use among US mobile phone owners: A national survey. JMIR mHealth and uHealth, 3(4), e101. doi:10.2196/mhealth.4924

Liang, D., Han, H., Du, J., Zhao, M., \& Hser, Y. (2018). A pilot study of a smartphone application supporting recovery from drug addiction. Journal of Substance Abuse Treatment, 88, 51-58. doi:10.1016/j.jsat.2018.02.006

Livingston, M. J., \& Callinan, S. (2015). Underreporting in alcohol surveys: whose drinking is underestimated? Journal of Studies on Alcohol and Drugs, 76(1), 158 164. https://doi.org/10.15288/jsad.2015.76.158

Mares, M., Gustafson, D. H., Glass, J. E., Quanbeck, A., McDowell, H., McTavish, F., .. . Ward, V. (2016). Implementing an mHealth system for substance use disorders in primary care: 
A mixed methods study of clinicians' initial expectations and first year experiences. $B M C$ Medical Informatics and Decision Making, 16(1), 126. doi:10.1186/s12911-016-0365-5

Mental Health America. Addictions. (2018, May 10). Retrieved from http://www.mentalhealthamerica.net/addictions

Middlesex-London Health Unit. (2017, November 17). What's a Standard Drink? Retrieved from https://www.rethinkyourdrinking.ca/what-is-a-standard-drink/

Miller, M. (2015, February 13). American Society of Addiction Medicine. Retrieved from https://www.asam.org/QualityScience/publications/magazine/read/article/2015/02/13/the-relevance-of-twelve-steprecovery-in-21st-century-addiction-medicine

Monney, G., Penzenstadler, L., Dupraz, O., Etter, J., \& Khazaal, Y. (2015). mHealth app for cannabis users: Satisfaction and perceived usefulness. Switzerland: Frontiers Research Foundation. doi:10.3389/fpsyt.2015.00120

Mulhauser, K., Weinstock, J., Ruppert, P., \& Benware, J. (2018). Changes in neuropsychological status during the initial phase of abstinence in alcohol use disorder: Neurocognitive impairment and implications for clinical care. Substance use \& Misuse, 53(6), 881-890. doi:10.1080/10826084.2017.1408328

Muroff, J., Robinson, W., Chassler, D., López, L. M., Gaitan, E., Lundgren, L., . . Gustafson, D. H. (2017). Use of a smartphone recovery tool for latinos with co-occurring alcohol and other drug disorders and mental disorders. Journal of Dual Diagnosis, 13(4), 280290. doi:10.1080/15504263.2017.1348649 
Muroff, J., Robinson, W., Chassler, D., López, L. M., Lundgren, L., Guauque, C., . . Gustafson, D. H. (2019). An outcome study of the CASA-CHESS smartphone relapse prevention tool for latinx spanish-speakers with substance use disorders. Substance use \& Misuse, 112. doi:10.1080/10826084.2019.1585457

National Institute on Alcohol Abuse and Alcoholism. (2014). Treatment for Alcohol Problems: Finding and Getting Help. Retrieved from https://www.niaaa.nih.gov/publications/brochures-and-fact-sheets/treatment-alcoholproblems-finding-and-getting-help

Nunes, A., Limpo, T., \& Castro, S. L. (2019). Acceptance of mobile health applications: Examining key determinants and moderators. Frontiers in Psychology, 10, 2791. doi:10.3389/fpsyg.2019.02791

Qualtrics. (n.d.). Survey Protection. Retrieved from https://www.qualtrics.com/support/surveyplatform/survey-module/survey-options/survey-protection/

Quanbeck, A., Chih, M., Isham, A., \& Gustafson, D. (2014). Mobile delivery of treatment for alcohol use disorders: A review of the literature. Alcohol Research: Current Reviews, 36(1), 111-122.

Rho, M. J., Rho, M. J., Kim, H. S., Kim, H. S., Chung, K., Chung, K., . . Choi, I. Y. (2015). Factors influencing the acceptance of telemedicine for diabetes management. Cluster Computing, 18(1), 321-331. doi:10.1007/s10586-014-0356-1

Ringle, Christian M., Wende, Sven, \& Becker, Jan-Michael. (2015). SmartPLS 3. Bönningstedt: SmartPLS. Retrieved from http://www.smartpls.com 
Savic, M., Best, D., Rodda, S., \& Lubman, D. I. (2013). Exploring the focus and experiences of smartphone applications for addiction recovery. Journal of Addictive Diseases, 32(3), 310-319. doi:10.1080/10550887.2013.824331nsum

Sawares, A. S., Shen, N., Xue, Y., Abi-Jaoude, A., \& Wiljer, D. (2017). The impact of mobile apps on alcohol use disorder: A systematic review protocol. JMIR Research Protocols, 6(4), e49. doi:10.2196/resprot.6975

Schuster, L., Tossan, V., \& Drennan, J. (2017). Consumer acceptance of mHealth services: A comparison of behavioral intention models. Services Marketing Quarterly, 38(2), 115128. doi:10.1080/15332969.2017.1289791

Silver, L. (2019, February 5). Smartphone Ownership Is Growing Rapidly Around the World, but Not Always Equally. Retrieved from https://www.pewresearch.org/global/2019/02/05/smartphone-ownership-is-growingrapidly-around-the-world-but-not-always-equally/

Sobell, L. C., \& Sobell, M. B. (2004, August). Alcohol Consumption Measures. Retrieved from https://pubs.niaaa.nih.gov/publications/assessingalcohol/measures.htm

Statistics Canada. (2016, September 28). Heavy drinking. Retrieved from https://www150.statcan.gc.ca/n1/pub/82-229-x/2009001/deter/hdx-eng.htm

Statistics Canada (2018, June 26). Health Fact Sheets: Smoking, 2017. Retrieved from https://www150.statcan.gc.ca/n1/pub/82-625-x/2018001/article/54974-eng.htm 
Statistics Canada. (2018). Heavy drinking, by age group. Retrieved from https://www150.statcan.gc.ca/t1/tbl1/en/tv.action?pid=1310009611\&pickMembers[0]=1. 1 \&pickMembers[1]=3.1

Stockwell, T., Zhao, J., \& Macdonald, S. (2014). Who under-reports their alcohol consumption in telephone surveys and by how much? an application of the 'yesterday method' in a national canadian substance use survey. Addiction, 109(10), 1657-1666. doi:10.1111/add.12609

Sun, Y., Wang, N., Guo, X., and Peng, Z. (2013). Understanding the acceptance of mobile health services: A comparison and integration of alternative models. J. Electr. Commerce Res. 14, 183-200.

Tibenderana, P., Ogao, P., Ikoa-Odongo, J., \& Wokadala, J. (2010). Measuring levels of end users' acceptance and use of hybrid library services. International Journal of Education and Development using Information and Communication Technology, 6(2), 33-54.

Venkatesh, V., Morris, M. G., Davis, G. B., \& Davis, F. D. (2003). User acceptance of information technology: Toward a unified view. MIS quarterly, 27(3), 425-478. doi: $10.2307 / 30036540$

Venkatesh, V., Thong, J., \& Xu, X. (2012). Consumer Acceptance and Use of Information Technology: Extending the Unified Theory of Acceptance and Use of Technology. MIS Quarterly, 36(1), 157-178. Retrieved from www.jstor.org/stable/41410412

Vo, V., Auroy, L., \& Sarradon-Eck, A. (2019). Patients' perceptions of mHealth apps: Metaethnographic review of qualitative studies. JMIR mHealth and uHealth, 7(7), e13817. doi:10.2196/13817 
Williams, M. D., Rana, N. P., \& Dwivedi, Y. K. (2015). The unified theory of acceptance and use of technology (UTAUT): A literature review. Journal of Enterprise Information Management, 28(3), 443-488. doi:10.1108/JEIM-09-2014-0088

Winerman, L. (2013, June). Breaking free from addiction. Retrieved from https://www.apa.org/monitor/2013/06/addiction

Zhang, Melvyn W.B., Ward, J., Ying, John J.B., Pan, F., Ho, Roger C.M. (2016, February 4). The alcohol tracker application: an initial evaluation of user preferences. $B M J$ Innovations, ;2:8-13. doi:10.1136/bmjinnov-2015-000087

Zhao, J., Stockwell, T., \& Thomas, G. (2015). An adaptation of the yesterday method to correct for under-reporting of alcohol consumption and estimate compliance with canadian lowrisk drinking guidelines. Canadian Journal of Public Health / Revue Canadienne De Santé Publique, 106(4), e204-e209. doi:10.17269/cjph.106.4753

Zhou, L., Bao, J., Watzlaf, V., \& Parmanto, B. (2019). Barriers to and facilitators of the use of mobile health apps from a security perspective: Mixed-methods study. JMIR mHealth and uHealth, 7(4), e11223. doi:10.2196/11223

Zhu, Y., Jiang, H., Su, H., Zhong, N., Li, R., Li, X., . . Z Zhao, M. (2018). A newly designed mobile-based computerized cognitive addiction therapy app for the improvement of cognition impairments and risk decision making in methamphetamine use disorder: Randomized controlled trial. JMIR mHealth and uHealth, 6(6), e10292. doi: $10.2196 / 10292$ 